\title{
Bone and bone marrow disruption by endocrine-active substances
}

\section{Dimitrios Agas (1) Giovanna Lacava | Maria Giovanna Sabbieti}

School of Biosciences and Veterinary

Medicine, University of Camerino,

Camerino, Italy

\section{Correspondence}

Dimitrios Agas, School of Biosciences and Veterinary Medicine, University of Camerino, Via Gentile III da Varano, I-62032 Camerino (MC), Italy.

Email: dimitrios.agas@unicam.it

Funding information

FAR 2014/2015 University of Camerino, Grant/Award Number: BVI000014
Bone is a multifaceted dynamic tissue, involved in mobility, mineral metabolism, and mesenchymal or stromal and hematopoietic progenitor or stem cells breading. Recently, an endocrine role has been attributed to bone due to its ability to produce at least two hormones (osteocalcin and fibroblast growth factor 23) and to participate directly or indirectly in leptin, insulin, estrogens, and serotonin signaling; regulation; and action. Also, bearing in mind the enormous amounts of substances secreted by the different bone marrow cell types, it becomes understandable the contribution of bone tissue to systemic homeostasis. Besides, bone is a well-known estrogenresponsive tissue, reacting to environmental influences. Thus, it has been coined as a critical target of environmental xenoestrogens, known as endocrine-disrupting chemicals (EDCs). The exposure to EDCs results to disruption or imbalance of the systemic hormonal regulation of the skeleton including bone modeling and remodeling, local hormones, and cytokine or chemokine release. The present report highlights the harmful EDCs effects on bone tissue and provides up-to-date information of xenoestrogen action on proliferation, maturation, and homing of bone marrow inhabitants.

\section{KEYWORDS}

bone, bone formation, bone marrow, bone remodeling, EDC mechanistic pathways, endocrine disruptors, hematopoietic stem cells, mesenchymal stem cells

\section{1 | INTRODUCTION}

The development of many organ systems is based on gonadal hormone regulation, predominantly during the prepubertal and pubertal stage. The immune-hematopoietic and skeletal anatomophysiological entities are among those organs whose maturation is strictly related to hormone accomplishment. Physiological exposure to estrogens in childhood drastically determinates the final peak bone density in adulthood. In parallel, estrogens, through direct or indirect interactions, participate in bone and blood progenitor differentiation within the confines of the bone marrow.

Bone tissue is a dynamic ensemble of various cell types including mesenchymal-derived cells in late differentiation, such as osteoblasts, mature cells, such as osteocytes, and monocyte-derived cells, such as macrophages and osteoclasts. One of the foremost bone metabolic features is the bone renewal, usually referred to as remodeling. Bone remodeling is controlled by complex mechanisms and signaling cascades, which maintain skeletal homeostasis and bone anatomical structure (Agas, Marchetti, Douni, \& Sabbieti, 2015). Some of the main participants in this process are the parathyroid hormone (Hodsman et al., 2003; Sabbieti, Agas, Santoni, et al., 2009; Sabbieti, Agas, Xiao, et al., 2009), the fibroblast growth factor 2 (FGF2; Naganawa et al., 2006, 2008), the bone morphogenetic proteins (BMPs) (Rosen \& Wozney, 2002; Sabbieti et al., 2013) the prostaglandins (PGs; Agas, Marchetti, Capitani, \& Sabbieti, 2013; Sabbieti et al., 2010, 2008) as well as transcription factors and cytokines secreted within the intricate patchwork of the skeletal topography. The skull, hips, vertebrae, ribs, and long bone cavities encompass a fine-tuned multicellular system; the bone marrow consists of mesenchymal or stromal and hematopoietic progenitor or stem cells, and other components including neuronal stem cells, reticular adventitial cells, endothelial cells, and mature blood cells 
(Agas et al., 2015). The organization of the above-mentioned microenvironment in well-defined operative microhabitats, identified as "niches," and their physical interactions ensure the functional dimension of the bone tissue. As explicable, skeleton properties go far beyond support mobility and control calcium and phosphorus homeostasis and fulfill the systemic metabolic demands. For instance, bone accommodates stem cells and cells with a plasticity grade (e.g., mesenchymal stem cells [MSCs]), which, by releasing cytokines or chemokines, growth factors and other molecules, participate in differentiation or homing or egression of the blood constituents (Agas et al., 2015). Furthermore, recent findings on bone physiology have ascribed to this tissue a ductless gland potential. Namely, osteoblasts produce osteocalcin, essential for bone remodeling but also critical in regulating (i) glucose metabolism via increase of insulin sensitivity or secretion, (ii) energy expenditure through the modulation of peroxisome proliferation-activated receptor $\gamma$ (PPAR $\gamma$ ) activity and glucose utilization, and (iii) induction of testosterone production in Leydig cells of the testes (Guntur \& Rosen, 2012). Osteocytes, in turn, produce FGF23, which monitors bone mineralization and adjusts systemic phosphate concentrations at the kidney proximal tubule and at the intestinal level (Fukumoto \& Martin, 2009).

Based on the above findings, the contribution of bone and bone marrow toward the whole systemic physiology, but also the importance of the different cell niches within this microenvironment characterized by functionality, integrity, and dependency, is clear. These idiosyncrasies have been attributed to the skeleton features as endocrine gland. Likewise, it is relevant that bone is an estrogen-responsive tissue and responds to environmental influences (Spelsberg, Subramaniam, Riggs, \& Khosla, 1999). Skeletal homeostatic preservation is disrupted after exposure to environmental toxicants, known as xenobiotic (xenoestrogens) or endocrine-disrupting chemical (EDCs).

The concept of the EDCs is based on the inappropriate modulation of the endocrine system at the circulatory (hormone interaction) and/or the transcriptional level (Tabb \& Blumberg, 2006). Within a broad scenario, the environmental xenoestrogens interfere with the endogenous hormone production and act as selected regulators of thyroid hormones, estrogen, androgen and a plethora of other receptors (Schantz \& Widholm, 2001). The harmful EDCs outcomes lead to various metabolic disorders such as diabetes type 2 and obesity, hormone-related cancers and disturbance in the reproductive apparatus. It is noteworthy that exposure to EDCs exposure in utero or in early life stages can induce organ abnormalities, behavioral disorders and tumor formation (Swedenborg, Ruegg, Makela, \& Pongratz, 2009). At the bone tissue level EDCs can exert deleterious effects both on the bone remodeling process and on bone intramural hormone production and, as a consequence, on the release of systemic hormones, cytokines, chemokines and growth factors (Agas, Sabbieti \& Marchetti, 2013). Modern research has shown that xenobiotics could also disrupt stem cell fate at multiple levels, as well as bone marrow mesenchymalstromal stem-progenitor cell differentiation and bone marrow niche organization (Agas, Sabbieti, et al., 2013; Annab et al., 2012).
EDCs have been classified into distinct families based on their chemical properties and exert singular effects on organs and tissues. Some paradigms of bone-disrupting environmental compounds are the perfluoroalkyl substances (PFASs), the phthalate esters, the dioxin and dioxin-like compounds, the diethylstilbestrol (DES), the bisphenol A (BPA), the organotin compounds and the alkylphenols. This report highlights recent findings related to the effects of these environmental chemicals on bone and the bone marrow, providing a molecular scenario of their action.

\section{2 | NEW INSIGHTS INTO THE MECHANISMS OF ACTION FOR EDCS}

\section{1 | Molecular cascades and epigenetic EDCs targets}

EDCs have the ability to interfere with the hormonal systems, often with complex dose-response curves, and to involve multiple signaling networks. It is known that EDCs exert agonistic or antagonistic effects on hormone receptors by disrupting their biosynthesis and thus hormone delivery to target tissues. EDCs can selectively bind the nuclear receptors (NRs), predominantly the androgen and estrogen receptors (ERs) but also the glucocorticoid receptor (GR), the mineralocorticoid receptor, the thyroid hormone receptors, the retinoid $X$ receptor (RXR) and the PPARs (Swedenborg et al., 2009). The direct or indirect EDCs-receptor interaction triggers numerous signaling cascades and culminates, in certain cases, in epigenetic alterations such as DNA methylation and histone acetylation.

NRs are important regulators of several epigenetic patterns: chromatin states are under the control of ERs and the androgen receptor (Martens, Rao \& Stunnenberg, 2011). Furthermore, these receptors, together with GRs and the aryl hydrocarbon receptor $(\mathrm{AhR})$, regulate DNA methylation at a specific gene locus through interactions with DNA methyltransferases (DNMTs; Kouzmenko, Ohtake, Fujiki \& Kato, 2010). Bearing in mind the above consideration, it is possible that the epigenetic effects elicited by exposure to xenoestrogens can be mediated by their binding to and interference with NRs functions. Accordingly, BPA alters DNA methylation patterns in a ERs dependent way (Kitraki, Nalvarte, Alavian-Ghavanini, Rüegg, 2015; Jorgensen, Alderman, \& Taylor, 2016), whereas 2,3,7,8-tetrachlorodibenzo-p-dioxin (TCDD) recruits DNMT1 on the target gene site via interaction with AhR (Papoutsis, Selmin, Borg \& Romagnolo, 2015).

Altered expression of DNMTs upon exposure to EDCs causes genome-wide as well as gene-specific modifications in the methylation status (Jacobs, Marczylo, Guerrero-Bosagna \& Rüegg, 2017). As a consequence, gene expression is altered and phenotypic change arises: Rats perinatally exposed to BPA have increased Dnmt1 and decreased Gad67 (one of the enzymes responsible for GABA production) messenger RNA (mRNA) expression. Due to these deregulated expressions, anxiety and alterations in synaptic plasticity occur, conditions that are reversed by the administration of DNMTs 
inhibitor (5-aza-deoxycytidine) since it restores the expression level of Gad67 (Zhou, Chen, Chang, Bai \& Chen, 2013).

In addition, exposure to EDCs alters histone-modifying enzymes. In particular, the expression of histone deacetylases (HDACs) is upregulated upon exposure to dioxin, whereas binding of benzyl butyl phthalate (BBP) to sirtuins (SIRTs) 1 and 3 decreases their expression levels, and the expression of two SIRT-dependent mitochondrial biogenesis genes. These processes lead to augmented reactive oxygen species production. Finally, BPA activates the phosphatidylinositol 3-kinase (PI3K)-Akt signaling pathway in an NR-independent way, and triggers an increased phosphorylation and inactivation of histone methyltransferase enhancer of zeste homolog 2 (EZH2), and an increased phosphorylation and activation of the histone methyltransferase MLL1. Therefore, BPA alters the epigenetic status by induction of histone demethylation and histone methylation (Jacobs et al., 2017).

EDCs-induced epigenetic modifications at imprinted genes have been reported to cause impaired sperm and egg maturation and function. Notably, phthalate esters are able both to disturb the methylation pattern of these genes, and to modify the chromatin status at the promoter regions by histone modification. These chemicals may alter the folding of DNA around histones by directly binding to their tail, thus modifying the inactivation or activation status of the genes (Benjamin et al., 2017; Jacobs et al., 2017).

The epigenetic modifications caused by EDCs can be classified as transgenerational effects as they can be transmitted for up to four generations in rodents (Anway \& Skinner, 2006; Gore, Heindel, \& Zoeller, 2006). Accordingly, metabolic and reproductive diseases and behavioral transgenerational effects are induced by in utero exposure to xenoestrogens. Furthermore, transgenerational reproductive defects have been identified after exposures to benzo[ $\alpha]$ pyrene $(B \alpha P)$ in young mice through 6 weeks of age (Jacobs et al., 2017).

One of the most reviewed molecular pathways, due to its role in several metabolic features of chemical disruptors, such as $B \alpha P$, polychlorinated biphenyls (PCBs), polychlorinated dibenzofurans (PCDFs), polycyclic aromatic hydrocarbons (e.g. 3-methylcholanthrene [3-MC]) and dioxin, is the AhR signaling network (Swedenborg et al., 2009). For instance, AhR ligands, such as the xenobiotics 3-MC or $\mathrm{B} \alpha \mathrm{P}$, activate $\mathrm{ER}-\alpha$ and induce estrogen transcription and higher estradiol production (Arcaro et al., 1999; Ohtake et al., 2003). Besides, ER-xenobiotic elective affinities initiate estrogenic signals that, in turn, influence gene expression and hormone biosynthesis (Wetherill et al., 2007). Accordingly, ERs, such as ER- $\alpha$, ER- $\beta$, and the G-protein ER GPR30, are directly affected after exposure to octyphenol, BPA and brominated flame retardants, exposure leading to thyroid and androgen hormone production and impaired lipid homeostasis (Mårtensson et al., 2009; Swedenborg et al., 2009).

On the other hand, the AhR-EDCs complex can also cause enhanced catabolism of steroid hormones and thus hormone degradation (e.g. AhR-P450 enzymes complex triggers
17- $\beta$-estradiol hydroxylation; Tsuchiya, Nakajima \& Yokoi, 2005). Bearing in mind that $A h R$ is involved in glucose uptake and fattissue homeostasis, under physiological conditions, xenobiotics, such as dioxin, can increase the risk of diabetes type II and other metabolic syndromes (Fierens et al., 2003; Sato et al., 2008). Furthermore, dioxin-like compounds, such as PCB-77 stimulate adipocyte differentiation via AhR signaling activation. As a countercheck, in AhR(-/-) mice, the administration of PCB-77 had no effects on lipid deposition and body weight (Arsenescu, Arsenescu, King, Swanson \& Cassis, 2008).

Nonetheless, EDCs could also target the proteasome-mediated degradation complex and could compromise the function or production of NRs and coregulatory factors. For example, BPA impedes EP- $\beta$ degradation and therefore increases EP- $\beta$ protein bioavailability (Masuyama \& Hiramatsu, 2004). Another family of xenobiotics, the phthalate esters, is capable of disrupting the proteasome degradation of the nuclear pregnane $\mathrm{X}$ receptor and consequently causing imbalanced steroid hormone release in circulation (Masuyama, Inoshita, Hiramatsu \& Kudo, 2002). Thus, the action of EDCs is not only restricted to deterring proteasome metabolic features but, additionally, increasing hormone receptor availability by stimulating mitogen-activated protein kinases (MAPK) signaling cascades or/and by inhibiting HDAC activity, promoting new steroid receptor transcription (Tabb \& Blumberg, 2006).

Focusing on the molecular pathways involving EDCs-ERs, it is important to emphasize that both genomic nuclear ERs (nERs) and nongenomic membrane ERs (mERs) interact with xenoestrogens (Xu, Liu, Gu, Huang, \& Pan, 2017). These chemicals alter specific gene expression by binding to nERs within the cytosolic compartment. After hetero- or homo-dimerization of the receptors, the xenoestrogen-ERs complex translocates in the nucleus where it binds estrogen-response elements (EREs; Kumar et al., 1987; Mangelsdorf et al., 1995). Straightforwardly, by the modulation of the ERs-ERE interaction, xenoestrogens interfere with the interaction between the receptors and their coactivator-corepressor and thus alter gene expression. EDCs interference is not restricted to ERE-containing genes: indeed, additional transcription factors, including Sp1, AP-1 and NF-kB, interact with nERs. Xenoestrogens are able to modify the interaction of these transcription factors with ERs, thereby indirectly altering the transcription of non-ERE containing genes (Acconcia, Fiocchetti, \& Marino, 2017). Moreover, selective stimulation of estrogen-related receptors (ERRs) by xenoestrogens (but not endogenous estrogens) prompt them to compete with ERs for EREs, despite binding to ERR response elements, and subsequently to regulate gene transcription (Xu et al., 2017).

Nongenomic mERs signaling, generally faster than the genomic one, has been found to be modulated upon exposure to xenoestrogens. Indeed, these chemicals trigger ERs phosphorylation, which in turn activates several extranuclear signaling cascades, including the PI3K-Akt, ERK-MAPK, and p38-MAPK pathways (Acconcia et al., 2017). 


\subsection{Mechanistic pathways of EDCs on bone and bone marrow components}

Given the importance of estrogen and ER in skeletal formation in humans and mice (E. P. Smith et al., 1994; Windahl, Andersson \& Gustafsson, 2002), there is compelling evidence of the interference of xenoestrogens in estrogenic activity and consequently in the bone modeling and remodeling process. Purposely, 4-nonylphenol (4-NP) induces osteoblast apoptosis through either mitochondrial (by increasing the critical death or survival ratio bcl-2-like protein 4 [Bax]-B-cell lymphoma 2 [Bcl2]) or extrinsic apoptotic pathways (involving the proapoptotic proteins caspase 8-BH3-interacting domain death agonist [Bid]) and interferes with the survival effects of 17- $\beta$-estradiol. Also, 4-NP participates in the modulation of ERs receptors and strongly inhibits the upregulation of ERs induced by 17- $\beta$-estradiol (Sabbieti et al., 2011). In a similar manner, BPA competes for the 17- $\beta$-estradiol receptors, ER- $\alpha$ and ER- $\beta$, and, due to its capacity to be freely transferred across the placenta, could result in compromised skeletal formation in fetal rats (Kim et al., 2001; Moors, Diel \& Degen, 2006; Welshons, Nagel \& vom Saal, 2006). Focusing on $\mathrm{B} \alpha \mathrm{P}$ effects on osteoblasts, it has been demonstrated that this chemical activates the mitotic signaling cascade ERK-MAPK and PI3K-Akt, via ERs regulation (Tsai, Yang \& Liu, 2004). Similarly, two phthalate esters, BBP and di-n-butyl phthalate (DBP) mimic the effects of $17-\beta$-estradiol on rat osteoblasts and, by altering ERs accomplishment, induce the expression of proteins involved in proliferative signaling cascades (Agas et al., 2007).

Furthermore, EDCs can disturb bone homeostasis by modifying the differentiation commitment of MSCs. Notably, exposure to endocrine disruptors changes the epigenetic status of MSCs and shifts their developmental schedule in favor of adipogenesis. Indeed, BPA induces PI3K-Akt-dependent activation of the mTOR pathway in human preadipocytes, which in turn activates PPAR $\gamma$ and the transcriptional activator sterol-regulatory element-binding factor 1 (SREBF-1), important for adipogenesis and transcription of the PPAR $\gamma$ gene. In agreement, the expression levels of these genes have been found to be upregulated also by perinatal exposure to 4-NP (Bateman, Strong, McLachlan, Burow \& Bunnell, 2017).

Even if conventional ERs-induced pathways inhibit adipogenesis, it has been proven that exposure to BPA alone, or in combination with NP, promotes adipogenesis through ERs signaling. A lower concentration NP activates nonclassical ERs molecular cascades, which in turn induce the expression of adipogenic genes, such as PPAR $\gamma, a P 2, C / E B P \alpha$, and C/EBP $\beta$. At lower concentration, EDCs increase PPAR $\gamma$ action and alter ER downstream signaling, leading to preadipocyte differentiation and MSCs adipogenic commitment (Bateman et al., 2017).

As mentioned above, EDCs affect MSC osteogenic differentiation by inducing osteoblast apoptosis. Accordingly, exposure to 4-NP, $\mathrm{BBP}, \mathrm{DBP}$ and BPA decreases preosteoblast maturation and viability. Estradiol has been shown to induce MSC differentiation toward an osteogenic lineage and to increase MSC expression of osteogenic genes, including Runt-related transcription factor 2 (Runx2), alkaline phosphatase (ALP), collagen I, transforming growth factor $\beta 1$ (TGF- $\beta 1$ ), and BMP2. Moreover, several xenoestrogens, including 4-tert-octyphenol (OP), BPA, di(2-ethylhexyl)phthalate (DEHP), mono(2-ethylhexyl)phthalate (MEHP), DBP, and monobutyl phthalate, reduce estradiol levels. Given the important role of estradiol in the expression of osteoblastogenic genes, it can be deduced that its decline directly reflects the metabolic features MSCs (Bateman et al., 2017).

Finally, epigenetic alterations induced by xenoestrogens can be an additional issue that underlies the altered adipogenic-osteogenic differentiation of MSCs. Accordingly, BBP increases H3K9 acetylation and decreases its dimethylation. Additionally, upregulation of histone acetyltransferases and downregulation of HDACs expression have been observed. Collectively, these epigenetic changes in MSCs shift their differentiation schedule toward adipogenesis (Bateman et al., 2017). Similar results in terms of the fate of mice MSCs fate were found by Shoucri et al. (2017) using the obesogen tributyltin (TBT). Namely, TBT and RXR activators (rexinoids) strongly influenced MSCs lineage commitment. Importantly, TBT-induced RXR activation altered the expression of EZH2 and modified genome-wide histone 3 lysine 27 trimethylation (H3K27me3). This epigenetic bias directly reflects in reprogramming MSCs differentiation in favor of fat cells maturation (Shoucri et al., 2017).

Data on the signaling transduction mechanism of the effects of EDCs on bone in vitro and in vivo, in some cases, are contradictory depending on the normal or the pathological clinical profile of administration and the treatment protocols. For example, Hagiwara et al. (2008) have noted that 4-NP exposure in vitro (calvarial osteoblasts [COBs]) or in utero not only disrupted the bone cell homeostatic tableau and 17- $\beta$-estradiol bioavailability but also promoted calcification of pup sternebrae through a nonestrogenic mechanism. The complexity of xenobiotic molecular pathways in bone cells remains unclear and resolving the mode of action of these disrupting chemicals remains a challenge for further field investigations.

\section{3 | BONE AND BONE MARROW-DISRUPTING CHEMICALS}

\section{1 | PFASs}

PFASs consist of a class of chemicals that have been used for more than six decades in surfactant and polymer industries and specifically in protective water- and stain-resistant coatings on clothing, carpets, furnishing, food containers, and in firefighting foam (Fromme, Tittlemier, Völkel, Wilhelm \& Twardella, 2009). PFASs have been characterized as endocrine and metabolic disruptors and obesogens (Heindel et al., 2017). In fact, PFASs are deposited in the liver and the kidney and accumulate in the skeleton, giving rise to tumors, immunotoxicity, liver damage, spleen atrophy, adverse skeletal and reproductive outcomes, and developmental defects in animal models and humans (Cui, Zhou, Liao, Fu \& Jiang, 2009; Fisher, Arbuckle, 
Wade \& Haines, 2013; Post, Cohn \& Cooper, 2012; Yu et al., 2009). Notably, the U. S. National Health and Nutrition Examination Survey (NHANES) conducted in 2011-2012 uncovered that four PFASs, namely, perfluorooctanoic acid (PFOA), perfluorooctane sulfonic acid (PFOS), perfluorohexane sulfonic acid and perfluorononanoic acid, were detected in the serum of $97-100 \%$ sampled individuals aged 12 years or older (Lewis, Johns \& Meeker, 2015).

Current in vitro and in vivo studies on experimental animals have shown that PFOA directly targets bone and bone marrow cell residents. Specifically, pregnant mice were exposed orally to PFOA $0.3 \mathrm{mg} \cdot \mathrm{kg}^{-1} \cdot \mathrm{day}^{-1}$ throughout pregnancy, and female offspring were studied until the late age of 13 or 17 months. PFOA-exposed offspring showed increased femoral periosteal area, with a parallel decrease in the mineral density of tibias. It is noteworthy that PFOA accumulates in bone till old age and consequently exerts persistent deleterious effects on bone geometry and mineral density (Koskela et al., 2016). The PFOA induced distinct pathological scenarios in bone architecture, such as abnormal stimulation of bone resorbing osteoclasts (PFOA doses of 0.1-10 $\mu \mathrm{M}$ ), and at higher concentrations decreased the cell viability of quite all the participants of bone remodeling (Koskela et al., 2016). Moreover, in vitro approaches using preosteoblastic cultures and treated with 100 and $200 \mu \mathrm{M}$ of PFOA revealed diminished metabolic features from 7th to 10th day after chemical administration. On the other hand, low PFOA concentrations $(0.1-10 \mu \mathrm{M})$ stimulated osteoblast differentiation as shown by the increased expression of osteocalcin mRNA and the increased amount of calcium. In terms of the "bone-eating cells," PFOA ranging from 10 to $200 \mu \mathrm{M}$ increased osteoclast number, although high PFOA concentrations $(200 \mu \mathrm{M})$ reduced the area of resorption pits (Koskela et al., 2016). Definitely, here the authors faced with an imbalanced bone remodeling.

Additional findings shed light on the PFOS bioaccumulation microareas in the bone cavities and revealed that the bone marrow reservoir was more exposed to the chemical than cortical or trabecular bone in mice. Accordingly, male mice exposed for 5 days to PFOS (lowest dose of $0.031 \mathrm{mg} \cdot \mathrm{kg}^{-1} \cdot \mathrm{day}^{-1}$ ) showed immunotoxic outcomes comprising impaired hematopoietic stem cells (HSCs) differentiation and MSCs commitment (Bogdanska et al., 2011, 2014). Taking into account that the bone marrow microenvironment is characterized by an extraordinary interdependence and interconnectedness of all the stemprogenitor and mature inhabitants, it is reasonable to assume that the PFAs disrupts the marrow niche machinery. PFOS that target components within the bone marrow reservoir are depicted in Figure 1.

In terms of human health, a NHANES study performed between 2005 and 2008 in the United States found that a higher serum concentration of PFOS is associated with a decrease in total lumbar spine bone mineral density (BMD) predominantly in premenopausal women. Among the sample of 1,147 women (842 premenopausal and 305 menopausal), serum measures revealed PFOA and PFOS concentrations of 3.96 and $15.32 \mathrm{ng} / \mathrm{ml}$, respectively. These data represent the prevalence rates of osteoarthritis and osteoporosis in premenopausal women of $5.6 \%$ and $4.9 \%$, respectively, and $16.4 \%$ and $20.7 \%$ in menopausal women, respectively. PFOA and

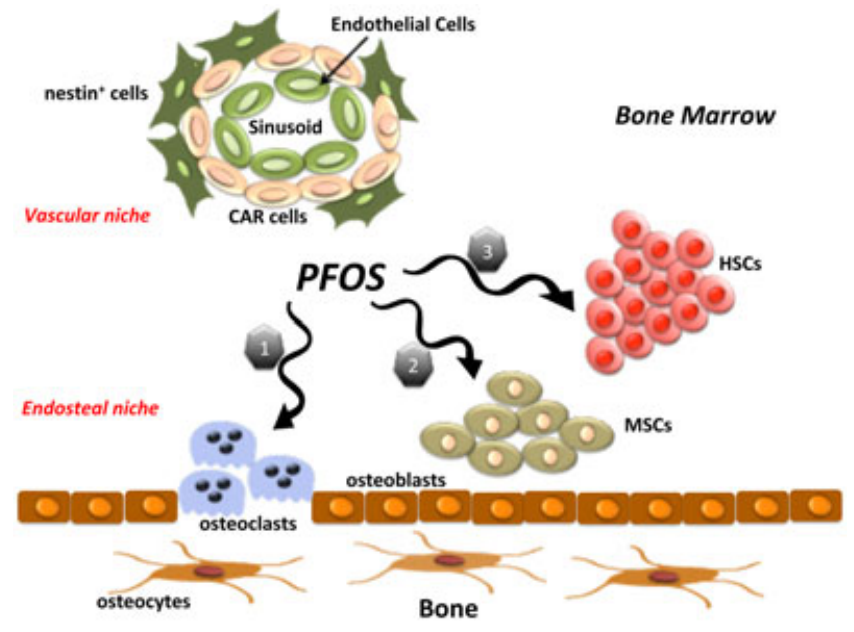

FIGURE 1 PFOS target cells within the bone marrow microenvironment. PFOS alters osteoblastic and osteoclastic metabolic features and disrupts the fine-tuned bone remodeling process (1). PFOS can also reprogram the differentiation schedule of the MSCs (2) and the HSCs (3), disrupting the physiological supply of osteoblasts and hematopoietic components. CAR, CXCL12-abundant reticular cells; HSC, hematopoietic stem cell; MSC, mesenchymal stem cell; PFOS, perfluorooctane sulfonic acid [Color figure can be viewed at wileyonlinelibrary.com]

PFOS serum concentrations were also detected in males (4.7 and $19.23 \mathrm{ng} / \mathrm{ml}$, respectively), with higher serum PFC concentrations observed in patients older than 60 years of both sexes (L. Y. Lin, Wen, Su, Chen \& Lin, 2014). The above findings suggest effects of low-dose PFASs in humans, which comprise severe forms of osteopenia, correlating PFASs serum concentration and BMD.

\section{2 | BPA}

BPA (4,4'-isopropylidenediphenol), is a class of synthetic monomers. BPA is the major component of epoxy and polystyrene resins broadly used in protective coatings, in consumer products such as foodpackaging and the beverage bottle industry, and in dentistry for dental sealants (Staples, Dome, Klecka, O’Block \& Harris, 1998). Halogenated derivatives, such as tetrabromobisphenol $A$, are used as flame retardants for building material. Last years, BPA was also applied in thermal paper used for the production of cash and billing receipts in very high concentration ( $20 \mathrm{mg} B P A / g / p a p e r)$. Due to its widespread environmental distribution, BPA has been detected in the concentration range of $0.1-10 \mathrm{ppb}$ in human blood and fetal tissues, and BPA metabolites can be found in almost everyone's urine (Hormann et al., 2014; Ikezuki, Tsutsumi, Takai, Kamei \& Taketani, 2002). Early studies termed BPA a xenoestrogen because it can exert estrogenic effects through the classical $n E R s$ with $\sim 10,000$ times less affinity than $17-\beta$-estradiol acting as a selective ER modulator and disruptor of the endocrine functions. Nonetheless, BPA initiates prompt responses via ERs presumably associated with the plasma membrane. These receptors can stimulate rapid signaling cascades at concentrations between $1 \mathrm{pM}$ and $1 \mathrm{nM}$ (Matthews, Celius, Halgren, \& Zacharewski, 2000; Watson, Jeng, \& Kochukov, 2010; Welshons et al., 2006). Further findings have 
shed light on the potential of BPA and derivatives in indirect AhR-mediated actions on steroid synthesis and metabolism (BonefeldJørgensen, Long, Hofmeister \& Vinggaard, 2007). As hitherto established, chronic BPA exposure has been associated with reproductive and cardiovascular diseases, cancer, and metabolic disorders (de Coster \& van Larebeke, 2012; Rochester, 2013).

The adverse effects BPA on embryofetal skeletal development were studied by Kim et al. (2001) in rodents, after maternal exposure to this chemical from 1 to 20 days of gestation. Administration of high BPA doses of $1,000 \mathrm{mg} / \mathrm{kg}$ during pregnancy resulted in significant maternal toxicity; in addition, the number of ossification centers of metacarpals, metatarsals, phalanges, and sternebrae was significantly decreased. At lower BPA doses of 100 and $300 \mathrm{mg} / \mathrm{kg}$, minimal fetotoxicity and random skeletal variations comprising enlarged fontanel, cervical rib, short 13th rib, short supernumerary rib and wavy rib, misshapen sternebra, sacral and caudal vertebra variations and impaired bipartite ossification of thoracic centrum, hemicentric thoracic centrum, dumbbell ossification of the thoracic centrum and incomplete ossification of the pubis were observed. Although the above-mentioned BPA effects on the skeleton did not have an overall statistical validity in lower BPA experimental doses, the direct effects of BPA on embryonic bone formation are dose related and can induce retardation on bone ossification (lower dosage of $85,100,125$, and $300 \mathrm{mg} / \mathrm{kg}$ during gestation days 1-15) or disruption of skeletal development (higher doses of 1,000 mg/kg; Kim et al., 2001).

The deleterious role of BPA in bone metabolism remains a highly controversial subject. Some reports have found that BPA treatment at doses of $0.1 \%$ BPA-diet for 5 months prevented bone loss in mice lacking the Cyp19 gene, and therefore, estrogen production. In this case, in an estrogen-lacking scenario, the oucomes of BPA were not toxic and, as opposed to what might be assumed, served an estrogenlike function in skeletal metabolism and bone mass maintenance (Toda, Miyaura, Okada, \& Shizuta, 2002).

Another report showed that the administration of BPA exerted effects on femoral geometry and biomechanical strength. BPAtreated mice from gestation day 11 to postnatal day 12 at a dose of $10 \mathrm{mg} \cdot \mathrm{kg}^{-1} \cdot \mathrm{day}^{-1}$, showed increased femur length: $2.3 \%$ in males and $1.0 \%$ in females (Pelch, Carleton, Phillips \& Nagel, 2012). The above findings were further confirmed by recent studies on bone development in both BPA-exposed male and female offspring. Administration of doses as low as $25 \mathrm{~g} \mathrm{BPA} \cdot \mathrm{kg}^{-1} \cdot \mathrm{day}^{-1}$ or $5,000 \mathrm{~g} \mathrm{BPA} \cdot \mathrm{kg}^{-1} \cdot \mathrm{day}^{-1}$ to mice dams altered the femoral geometry in developmentally exposed offspring. Interestingly, the femur of the female BPA-exposed offspring was elongated and, instead, the femoral diaphyseal cortex of male offspring was significantly thicker, suggesting a sexually dimorphic effect (Lejonklou et al., 2016). Moreover, pregnant rats were exposed to BPA at doses similar to the range of daily human exposure $\left(0.1-1.5 \mu \mathrm{g} \cdot \mathrm{kg} \mathrm{BW}^{-1} \cdot \mathrm{day}^{-1}\right)$. It is noteworthy that administration of BPA of only $0.5 \mu \mathrm{g} \cdot \mathrm{kg}^{-1} \cdot \mathrm{day}^{-1}$ via drinking water from gestational day 3.5 and throughout lactation (postnatal day 21), led to shorter femurs, with reduced trabecular area and total cross sectional area in male offspring, indicating the sex-sensitive effects of BPA (Lind et al., 2017).
In terms of the pathological outcomes in the bone marrow microenvironment after BPA exposure, Tiwari et al. (2012) found that this chemical exerts cytotoxic but not mutagenic effects, and target the micronucleated polychromatic erythrocyte metabolism. Namely, oral administration of BPA to adult male and female rats once a day for 6 days, at doses of $10 \mathrm{~g}, 5 \mathrm{mg}$, and $50 \mathrm{mg} / \mathrm{kg}$ body weight (BW), increases the clastogenic activity in bone marrow cells and DNA fragmentation in blood lymphocytes. The oxidative stress induced by the action of BPA within the bone marrow could be one of the possible mechanisms of BPA-induced genotoxicity. In line with this, some authors claimed that BPA exposure affects bone marrow gene expression such as Ppary (a gene with a key role in adipogenesis) and Adamts1 (linked to skeletal development), in a sex-related manner (Lind et al., 2017). Other in vitro studies found that BPA-treated bone marrow MSCs for 5 days, at doses of $100 \mathrm{nM}$ or $1 \mathrm{M}$, caused marked alterations in their metabolic features. BPA, on the one hand, might enhance the proliferation of MSCs and, on the other, might decrease the renewal capacity of MSCs. Moreover, this compound augments adipogenic differentiation and alters the transcriptomic MSCs profile (Strong et al., 2016). Additionally, BPA can abolish the fine-tuned osteoblastogenic and osteoclastogenic differentiated schedule and reduce the key role of bone remodeling markers such as receptor activator of nuclear factor-kappa B (RANK), Runx2, and osterix (Osx), inducing adipogenesis (Hwang et al., 2013). So far, it can be assumed that the BPA induces impaired communication of the bone marrow elements within a remodeling scenario at the endosteal level. The epigenetic BPA targets and its action within bone marrow confines are shown in Figure 2.

The range of daily exposures was shown to be $0.1-1.5 \mu \mathrm{g}$ BPA $\cdot \mathrm{kg}^{-1} \cdot \mathrm{day}^{-1}$ in humans in different countries between the years 2006 and 2010 (Geens et al., 2012), although the diffusion has declined in U. S. adults during the period 2000-2014 (Ye et al., 2014). But the BPA experimental plateau on laboratory animals and the limited human observation are not reassuring for the human health.

Given that a minimal dose of BPA administration such as $25 \mathrm{~g} \cdot \mathrm{kg} \mathrm{BW}^{-1} \cdot \mathrm{day}^{-1}$, can alter the bone and consequently the bone marrow homeostasis in rodents and considering that (i) the humanequivalent dose used by the European Food Safety Authorities is $609 \mathrm{~g} \mathrm{BPA} \cdot \mathrm{kg}^{-1} \cdot \mathrm{day}^{-1}$, establishing a temporary theoretically daily intake of $4 \mathrm{~g} \mathrm{BPA} \cdot \mathrm{kg}^{-1} \cdot \mathrm{day}^{-1}$ (European Food Safety Authority, 2015), and (ii) the current FDA reference dose for BPA is $50 \mathrm{~g} \cdot \mathrm{kg}^{-1} \cdot \mathrm{day}^{-1}$, become reasonable to questioned about the bone and bone marrow developmental risk after BPA exposure in humans. In fact, the median urinary BPA in Germany children has been reported to be $1.76 \mu \mathrm{g} / \mathrm{g} \mathrm{Cr}$ and the median BPA concentrations in different populations can vary between 1.7 and $2.4 \mu \mathrm{g} / \mathrm{L}$. Notably, the median adjusted-BPA concentration in Thai children with advanced puberty and obesity was detected to be between 1.74 and $1.44 \mu \mathrm{g} / \mathrm{g}$ $\mathrm{Cr}$ (Supornsilchai et al., 2016).

\section{3 | Alkylphenols}

Alkylphenol ethoxylates (APEs) are xenoestrogens belonging to the class of nonionic surfactants and they are used in the production of 
(a)

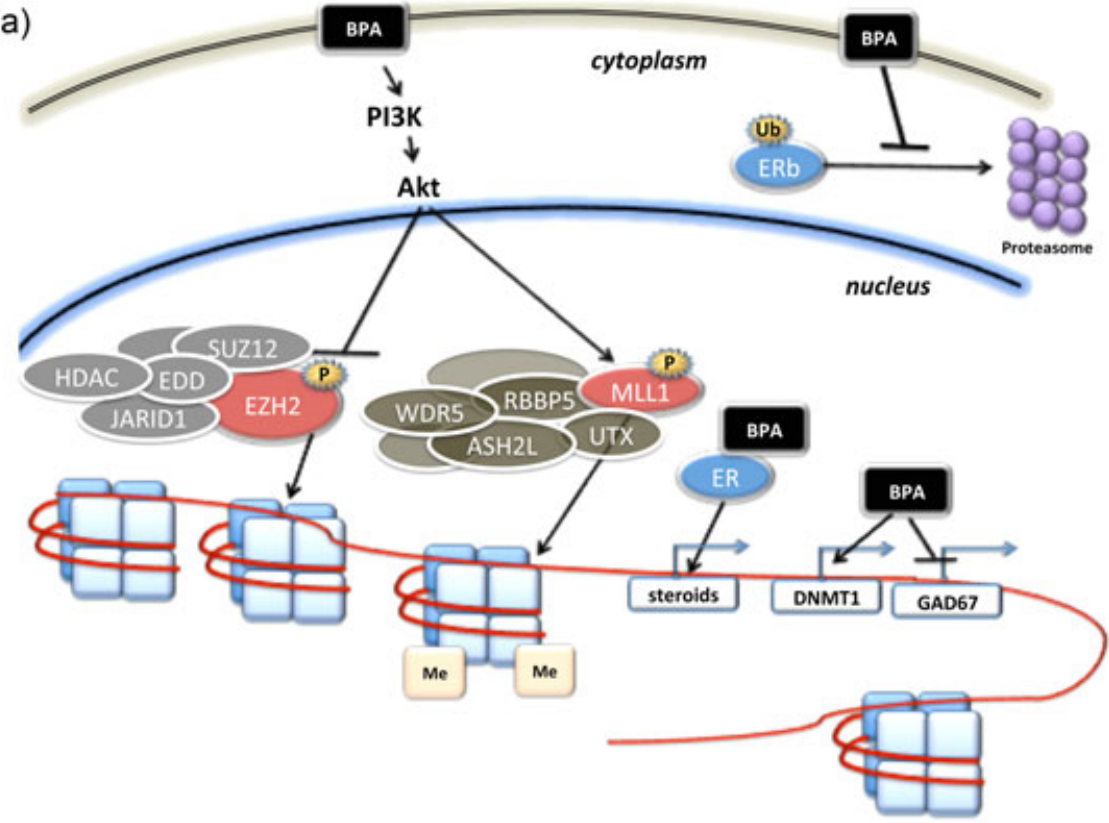

(b)

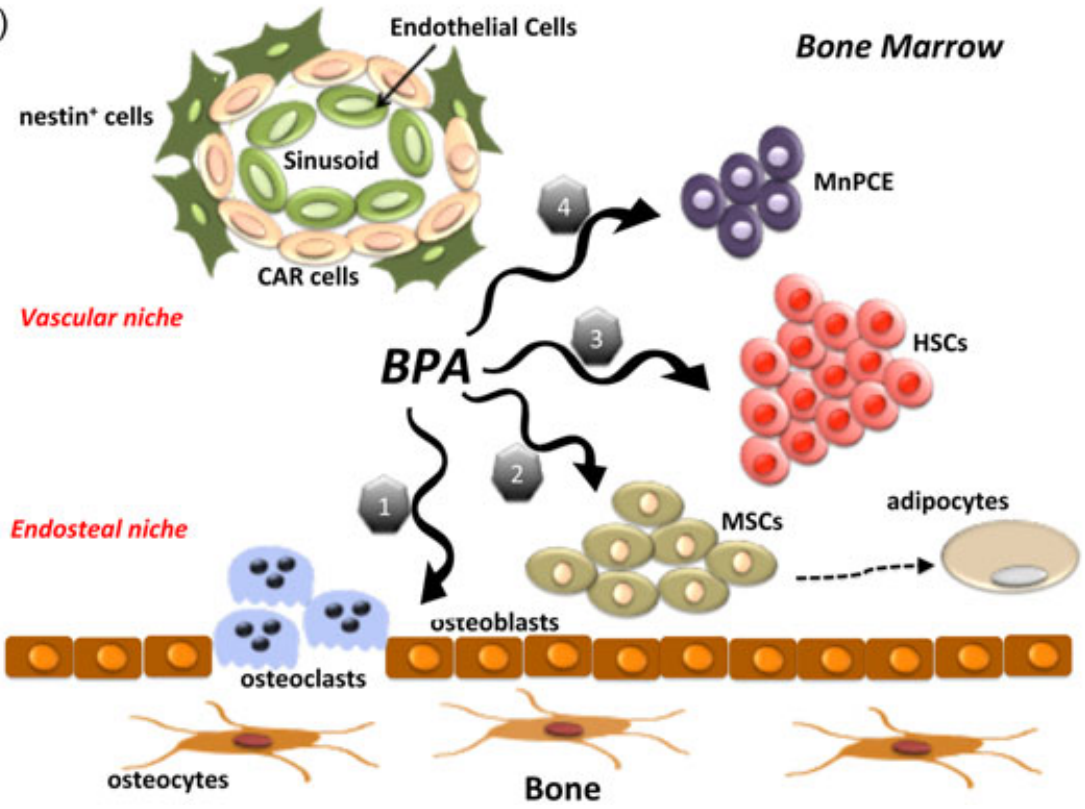

FIGURE 2 BPA epigenetic targets and disrupting activity in the bone marrow. (a) BPA alters DNA methylation patterns in an ERs-dependent way. Furthermore, BPA activates the PI3K-Akt signaling pathway in an NR-independent way, and induces inactivation of histone methyltransferase $\mathrm{EZH} 2$, with concurrent activation of the histone methyltransferase MLL1. The chemical augmented Dnmt1 and reduced Gad67 transcription and impeded EP- $\beta$ degradation, increasing EP- $\beta$ protein bioavailability. (b) BPA disrupts the bone remodeling process downregulating key role participants, such as Runx2 and Osx (1). BPA enhances the proliferation of MSCs, with a concurrent decrease in the renewal capacity of MSCs. BPA switch differentiation MSCs schedule toward adipogenesis and alters the transcriptomic MSCs profile (2). BPA is involved in HSCs commitment (3) and targets the metabolism of micronucleated polychromatic erythrocytes (MnPCE) (4). BPA, bisphenol A; ER, estrogen receptor; EZH2, enhancer of zeste homolog 2; HSC, hematopoietic stem cell; MSC, mesenchymal stem cell; NR, nuclear receptor; PI3K, phosphatidylinositol 3-kinase; Runx2, Runt-related transcription factor 2 [Color figure can be viewed at wileyonlinelibrary.com] paints, detergents, plastics and pesticides (Nimrod \& Benson, 1996). The major degradation products of APEs are OP and 4-NP, which are widely diffused in the environment and commonly found in the wastewater and sludge of sewage treatment works, in river sediments and in drinking water (Giger, Brunner \& Schaffner, 1984; Hernando et al., 2004). The APEs estrogenic-like effects and their toxicity have been identified in various tissues, such as the liver, kidney, spleen, blood (Barlas \& Aydogan, 2009; Hsieh et al., 2009) and bones.

During the last decade, the disrupting action of APEs on bone volume and bone marrow homeostasis has been at the forefront of the studies in the field of EDCs. It is noteworthy that NP can increase $\mathrm{Ca}^{++}$ levels, induce $\mathrm{Ca}^{++}$-independent cell death in human osteosarcoma cells (Wang et al., 2005), and affect the immune system via impaired Th1 cell development and Th2 overproduction (Iwata, Eshima, Kagechika \& Miyaura, 2004).

Kamei, Miyawaki, Sakayama, Yamamoto, and Masuno (2008) showed that the administration of OP in mice prenatally and postnatally decreased periosteal and endosteal bone formation at the femur diaphyseal level and blocked bone growth in width. Specifically, pregnant mice were exposed to drinking water containing OP, $1 \mathrm{~g} / \mathrm{ml}$ (lower dose) or $10 \mathrm{~g} / \mathrm{ml}$ (higher dose), from gestational day 10 and during the lactation period. Pups were also exposed to both doses of the chemical after weaning. Among the offspring the female skeleton, with prevalence at the expense of the male, resulted affected by OP; in fact, in female pups, bone formation markers such 
as osteoclacin were downregulated (serum osteocalcin levels were fall down at 30\%). Accordingly, reduced femur circumference and impaired long bone formation were observed predominantly after $1 \mathrm{~g} / \mathrm{ml}$ of OP exposure. The low-dose OP-treated group also showed lesser ALP production, which further confirms the compromised bone deposition and the reduced diaphyseal perimeter. At higher doses, adverse effects of OP were likewise protracted to the trabecular area with consequent disruption of the cancellous bone network. Notably, although cortical bone width was significantly diminished, with a consequent reduction in bone strength, the length of long bones was preserved (Kamei et al., 2008).

Recently, some reports have shown that the administration of NP or OP $(0.1 \mathrm{mg} / \mathrm{kg} \mathrm{BW})$ to pregnant mice at precise time points $(10,12$ and 14 days postcoitus) induced accelerated ossification of the sternebrae and slight or considerable alterations in metatarsal, metacarpal and sopraoccipital ossification of fetuses at 17 days postcoitus (Hagiwara et al., 2008).

The abnormal ossification of the sternebrae after OP exposure, has been supported by additional in vitro experimental designs, which showed that the administration of NP or OP in a dosedependent manner (from $10^{-9}$ to $10^{-6} \mathrm{M}$ ), inhibited osteoclast formation in a coculture system of mouse bone marrow cells and in mouse osteogenic stromal cells ST2. The chemical-induced weakened osteoclast differentiation, resulted at $50 \%$ after $10^{-8} \mathrm{M}$ of NP or OP treatment, and these experimental doses did not affect the metabolic features of the osteoblastic cell line (Hagiwara et al., 2008).

In contrast, Miyawaki et al. (2008) reported that high alkylphenol doses, in vitro, disrupted the fine-tuned differentiation machinery of the multipotent $\mathrm{C} 3 \mathrm{H} 10 \mathrm{~T} 1 / 2$ cells into osteoblasts. In particular, OP-treated C3H10T1/2 cells $(15 \mathrm{~g} / \mathrm{ml}$ for 7 days) showed $81 \%$ reduced ALP activity and decreased expression of TGF- $\beta 2$, an essential factor for osteoblast differentiation. Moreover, PPAR $\gamma$, the main adipocyte maturation marker, has been found to be upregulated after OP treatment. Due to these observations, the authors concluded that alkylphenol exposure interrupted the multipotent features of the considered cell line, causing a substantial lineage shift toward adipocyte differentiation (Miyawaki et al., 2008).

Other studies have focused on the capacity of the alkylphenols to interfere with the proliferative-survival metabolic features of $17-\beta$-estradiol on mouse COBs. Therefore, COBs exposure to high NP doses $\left(10^{-4} \mathrm{M}\right)$ in vitro, leads to massive cell death, whereas the lower doses $\left(10^{-5}\right.$ and $\left.10^{-6} \mathrm{M}\right)$ activate both the extrinsic and the intrinsic apoptotic pathway. A number of regulatory apoptotic markers, such as the $\mathrm{Bax}-\mathrm{Bcl} 2$ ratio, caspase 9 , caspase 3 , caspase 8 and Bib were found to be increased in COBs after NP treatment. Moreover, studies on osteoblast viability indicated that concomitant administration of NP $\left(10^{-6} \mathrm{M}\right)$ and $17-\beta$-estradiol $\left(10^{-7} \mathrm{M}\right)$ suppressed the upregulation of ERs induced by $17-\beta$-estradiol alone, indicating that NP overcome the physiological (anabolic) $17-\beta$-estradiol effects on COBs and substantially reduce the ERs differentiation-survival signals in osteoblasts (Sabbieti et al., 2011). Here, it has to be underscored that, similarly, exogenous estrogens during embryonic and fetal development might exert bone-disrupting effects. Recently, the effects of gestational 17- $\beta$-estradiol exposure on bone development were analyzed in porcine offspring. Low doses of 0.05 and $10 \mathrm{~g} \mathrm{E2/kg} \mathrm{BW,} \mathrm{referred} \mathrm{as} \mathrm{"acceptable} \mathrm{daily} \mathrm{intake"} \mathrm{and}$ "no observed effect level" in humans, induced sex-specific effects on bone development (Flöter et al., 2016).

On the basis of the above evidences, the harmful alkylphenol effects on bone marrow microhabitats and bone-forming cells. Thus, these xenobiotics disrupt the optimal balance between osteoblasts and osteoclasts and the well-defined bone remodeling process. The gene modifications alkylphenol-induced and their action in the bone marrow are depicted in Figure 3.

\subsection{Phthalate esters}

Phthalate esters are ubiquitous environmental contaminants characterized by a moderate resistance to degradation. The production of phthalate worldwide amounts to $>18$ billion pounds yearly. They are primarily used as plasticizers in the food industry, toys, car seats and blood bags (Blount et al., 2000; Group, 1986). The toxic potential of phthalates was identified many years ago (Mayer, Stalling, \& Johnson, 1972), in addition to their estrogen-mimic activity, which led to the classification of phthalates as potent endocrine disruptors (Harris, Henttu, Parker \& Sumpter, 1997; Jobling, Reynolds, White, Parker \& Sumpter, 1995).

Early studies have demonstrated that exposure to phthalate metabolites can cause a significant increase in skeletal malformations due to deformity of the thoracic vertebrae and fusion of the vertebral arches in rat fetuses (Ema, Itami \& Kawasaki, 1992). Besides, the deleterious effects of phthalate on bone and other tissues resulted in teratogenicity and embryo lethality, as observed after the administration of $2 \%$ of BBP in the diet during the first half of pregnancy in rats (Ema, Itami \& Kawasaki, 1993). Therefore, DBP exposure via gastric intubation in dams on gestation days 7-9, 10-12 or 13-15 and at various doses from 750 to $1,500 \mathrm{mg} \cdot \mathrm{kg}^{-1} \cdot \mathrm{day}^{-1}$, resulted in deformity of the vertebral column (higher doses), cleft palate and fusion of the sternebrae (median-lower doses). On evaluating the experimental evidences, it appears that the effects of DBP on bones were dose- and time dependent (Ema, Amano \& Ogawa, 1994). In agreement with this a more recent study in which pregnant rats were exposed via an oral gavage to di-isoheptyl phthalate (DIHP) at doses of 300 and $750 \mathrm{mg} / \mathrm{kg}$ on gestational days 6-20, unveiled noteworthy dose- and time-dependent effects. The harmful effects of DIHP were observed in the fetuses, which presented skeletal variations and malformations, such as rib and vertebral anatomical irregularities, particularly after exposure to DIHP at a high dose (McKee, Pavkov, Trimmer, Keller \& Stump, 2006). In agreement with this, administration of di-n-hexyl phthalate or dicyclohexyl phthalate by gavage in rats (at doses of 250, 500 and $750 \mathrm{mg} \cdot \mathrm{kg}^{-1} \cdot \mathrm{day}^{-1}$ and during gestational days 6-20) revealed sternebral and cervical anomalies, poor hyoid ossification and delayed ossification of the hindlimb proximal phalanges of fetuses (Saillenfait, Gallissot \& Sabaté, 2009). Other phthalate metabolites, such as di-n-heptyl phthalate and di-n-octyl phthalate, administered using the above-mentioned 
(a)

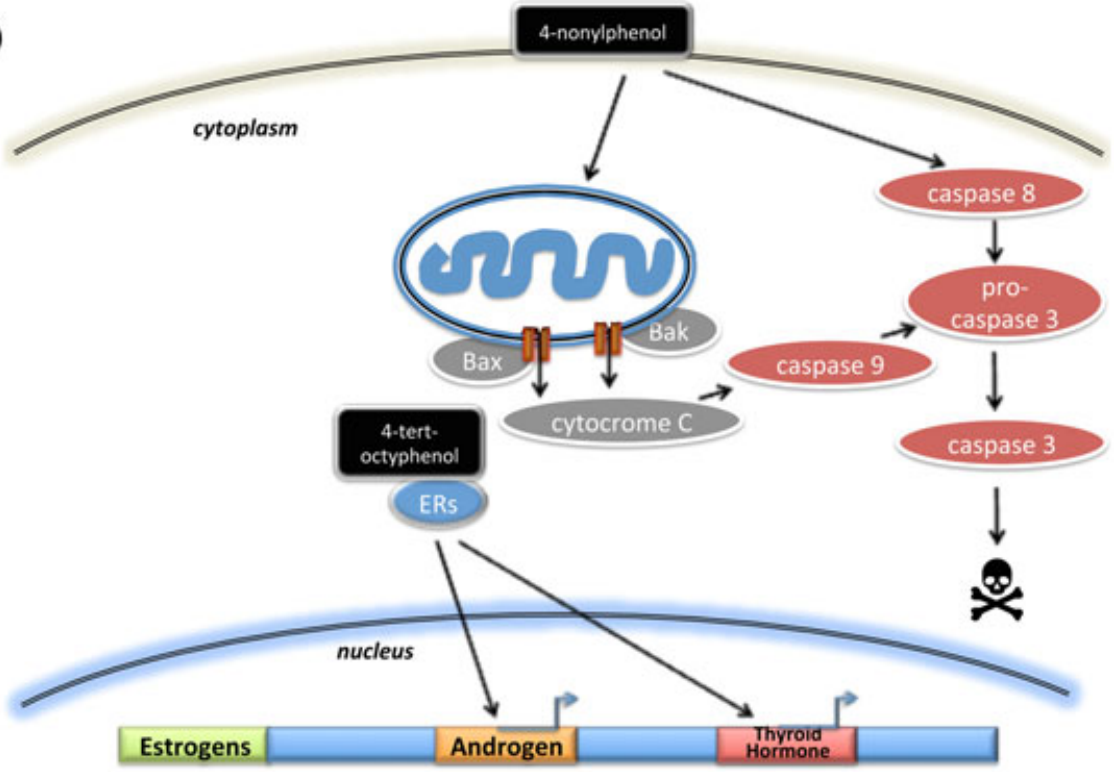

(b)

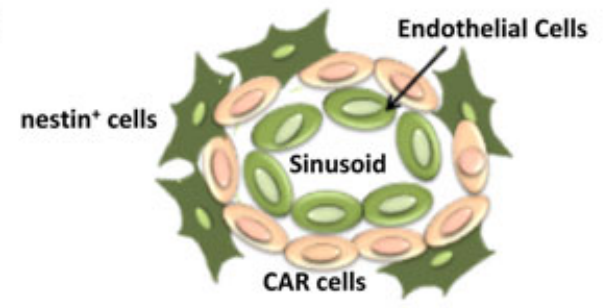

Vascular niche

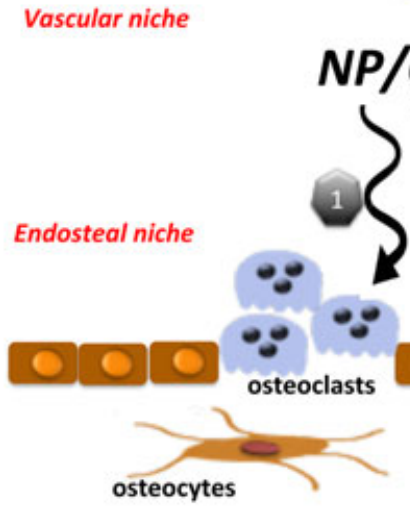

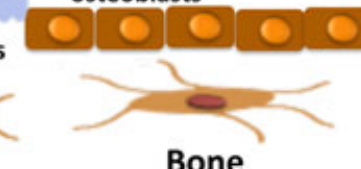

\section{Bone Marrow}

adipocytes

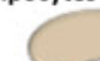

$\hat{i}$

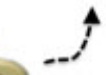

MSCs

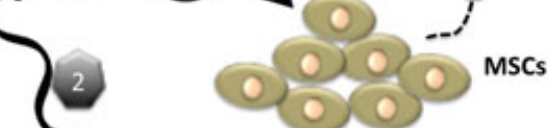

method, at doses of $0.25,0.50$, and $1 \mathrm{~g} \cdot \mathrm{kg}^{-1} \cdot \mathrm{day}^{-1}$, induced skeletal malformations in fetuses, such as supernumerary lumbar ribs and reduced forelimb proximal phalanges (Saillenfait, Roudot, Gallissot \& Sabaté, 2011).

In sum, on the basis of the in vivo effects of phthalate on skeletal formation reported so far, it can be deduced that exposure to different phthalate metabolites can cause marked changes in bone homeostasis and development.

The anabolic action of 17- $\beta$-estradiol on bone cells is well documented and it is also known that this estrogen regulates cell cycle factors, such as cyclin D3 and consequently osteoblast proliferation (Fujita et al., 2002). In this respect, it has been demonstrated that an in vitro BBP treatment $\left(10^{-6} \mathrm{M}\right)$ for $6 \mathrm{hr}$ in

FIGURE 3 NPs' potential target inhabitants within the bone marrow. (a) 4-NP induces osteoblast apoptosis through either mitochondrial or extrinsic apoptotic pathways and disrupts the survival effects of 17- $\beta$-estradiol. 4-NP and OP play a role in the modulation of ERs receptors and strongly inhibit the upregulation of ERs induced by $17-\beta$-estradiol and reduce estradiol levels (b). NP-OP inhibit osteoclast formation (1) and decrease osteoblast differentiation markers such as TGF- $\beta 2$, directly affecting osteoblast metabolism (2). Alkylphenol exposure interrupts the multipotent features of MSCs and shifts the lineage schedule toward adipocyte differentiation (3). ER, estrogen receptor; MSC, mesenchymal stem cell; NP: nonylphenol; OP, 4-tert-octyphenol; TGF- $\beta 2$, transforming growth factor $\beta 2$ [Color figure can be viewed at wileyonlinelibrary.com]

rat osteoblastic cultures induced increased D3 expression and abnormal cell proliferation via the agonistic effects of 17- $\beta$-estradiol (Agas et al., 2007). The above data are in agreement with other findings, which showed that the DEHP treatment (10 M) for $48 \mathrm{hr}$ in rat calvarial cultures augmented cell proliferation and decreased differentiated markers such as ALP, TAZ, Runx2 and collagen synthesis (Bhat et al., 2013).

Another report claimed that some phthalates exert dissimilar effects in different experimental models. Indeed, the in vitro treatment of $10^{-6} \mathrm{M}$ of BBP or DBP in mouse primary COBs led to upregulation of proapoptotic proteins, such as Bax, caspase 3 and caspase 9, and induced DNA damage and p53-mediated cell death (Sabbieti et al., 2009). Considering that in this study, the lowest 
effective concentration of phthalates was tested to minimize cell toxicity, it can be speculated that BBP and DBP can induce mutagenesis in mouse osteoblasts.

Early studies focused on the action of phthalate on the rat bone marrow homeostatic mechanisms revealed that BBP exposure decreased bone marrow cellularity and the ratio of the volume of hematopoiesis, and altered the adipocyte population (Agarwal, Maronpot, Lamb \& Kluwe, 1985).

Furthermore, reports on B-cell metabolism and immune cell development have shown remarkable data on the effects of phthalate within the marrow reservoir. Notably, primary cultures of bone marrow $\mathrm{B} 22 \mathrm{O}^{+} / \mathrm{CD} 43^{+} \mathrm{B}$ cells undergo apoptosis when treated with a metabolite of the ubiquitous phthalate DEHP, the MEHP, at doses ranging from 10 to $150 \mathrm{M}$ for $16 \mathrm{hr}$. The mechanism of the immunotoxic action of MEHP is based on its capacity to cooperate with an endogenous bone marrow natural PPAR $\gamma$ ligand agonist, the 15-deoxy- $\Delta^{12,14}-\mathrm{PGJ}{ }_{2}$, which is known to be an apoptotic agent in the early developmental stages of the B cell. Keeping in mind that (i) the bone marrow microenvironment contains elevated levels of the PG PPAR $\gamma$ agonist, which regulates the fate of the B lymphocyte maturation, and (ii) phthalate ester metabolites are PPAR $\gamma$ agonists, it can be assumed that exposure to DEHP and/or MEHP inhibits proliferation and induces apoptosis in developing $B$ cells, potentially via PPAR $\gamma$ signaling within the confines of the bone marrow (Schlezinger et al., 2004).

Recent findings have shown that the in vitro administration of MEHP ( $20 \mu \mathrm{M}$ for 7-10 days) induced lipid accumulation in mouse bone marrow-derived multipotent mesenchymal stromal cells and MEHP, acting as a PPAR $\gamma$ agonist, diverts the MSC differentiation pathway toward adipogenesis (Watt \& Schlezinger, 2015). These results clearly demonstrate that MEHP suppresses osteogenic MSCs commitment, upsetting the overall bone health in experimental animals. The epigenetic modifications caused by phthalates as well as the bone marrow inhabitants disrupted by their action are shown in Figure 4.

Given the disrupting effects phthalate on rodent bone and bone marrow, there is an urgent need to identify the potential association of these xenoestrogens with human bone metabolism. One of the few studies in humans, with the support of the three NHANES cycles (2005-2006, 2007-2008 and 2009-2010), showed that in postmenopausal women $(n=480)$ the urinary phthalate metabolites detected were negatively related to the total spine BMD. The phthalates involved were monoethyl phthalate (MEP), low-molecularweight metabolites of mono- $n$-butyl phthalate (MNBP), monoisobutyl phthalate (MIBP) and MEP and of estrogenic metabolites (MNBP, MIBP, MEP monobenzyl phthalate [MBZP]); interestingly, increased concentrations of phthalate metabolites corresponded to a linear decrease in spinal BMD (DeFlorio-Barker \& Turyk, 2016). Another report based on data from the 2005-2008 NHANES for 398 postmenopausal women observed that increases in the urinary mono-n-butyl phthalate, mono-(3-carboxypropyl)phthalate and MBZP quartiles were significantly associated with reduced total hip and femur neck BMD. The authors concluded that urinary phthalate metabolites were associated with low BMD and a high risk of osteoporosis in postmenopausal women (Min \& Min, 2014).

\section{5 | DES}

DES is a synthetic estrogen considered to be five times more potent than estradiol and identified as an ER- $\alpha$ activator with a similar affinity for the receptor as estradiol (IARC, 2012; Korach, Metzler \& McLachlan, 1978). Due to its characteristic as an estrogen agonist, DES was extensively used during the 1950 s and the 1960 s to prevent miscarriages and to suppress postpartum lactation. In the 1970s this compound was used in agriculture and it was removed in 1979 due to its harmful effects on children born to DES-exposed mothers; furthermore, the deleterious overall effects on mothers and daughters also included vaginal adenocarcinoma and development of various cancer (Greenberg \& Robert, 1982; Treffers, Hanselaar, Helmerhorst, Koster \& van Leeuwen, 2001). Exposure to DES can also induce epigenetic changes and subsequently transgenerational sequel effects (Titus-Ernstoff et al., 2010).

Although the use of DES utilization has increasingly decreased, many recent works have focused on its destabilizing effects on bone homeostasis. Accordingly, a 4-week administration of DES to male and female mice, at doses of $500 \mathrm{~g} / \mathrm{kg}$, induced increased trabecular bone formation in the metaphyseal area of the femur. In DES-treated males, hyperostosis was also found at the sternum level. Interestingly, fibro-osseous lesions (FOLs), characterized by accelerated bone resorption with concurrent fibroplasia and abnormal bone turnover, were also found. The FOL observed after DES exposure may have occurred due to the formation of preneoplastic lesions and highlights the capability of this chemical not only to induce impaired osteoclast formation but also to enhance cancerogenic effects on bone (McAnulty \& Skydsgaard, 2005).

Several studies have obtained comparable results on the effects of DES on bone mass and osteoclast maturation. Namely, female mice were injected with $100 \mathrm{~g} / \mathrm{kg}$ DES from Days 9 to 16 of gestation or, alternatively, pups received neonatal injections of $2 \mathrm{~g}$ of DES from Days 1 to 5 . In the DES-treated group, decreased osteoclast number and activity was observed, with consequent higher bone deposition and BMD (Migliaccio et al., 2000). In another in vivo investigation, female mice were treated with $2 \mathrm{mg} \cdot \mathrm{kg}^{-1} \cdot \mathrm{day}^{-1}$ DES for 4 months. The female DES-treated group showed higher femur and lumbar vertebrae (LV1-LV4) BMD; the opposite effects were found in the male DES-treated group, with no significant changes in BMD (Piekarz \& Ward, 2007). Furthermore, a subcutaneous DES injection $\left(2 \mathrm{mg} \cdot \mathrm{kg}^{-1} \cdot \mathrm{day}^{-1}\right)$ to mice from postnatal day 1-5 produced similar results. Female DES-treated mice showed stronger lumbar vertebrae due to increased BMD in contrast to the male DES-treated mice (Kaludjerovic \& Ward, 2008). Thus, it is clear that relatively high DES doses exert sex-specific effects and therefore influences bone homeostasis in a sex-related manner.

Although high doses of DES ameliorate female bone constitution at femoral and lumbar anatomical districts, some reports have claimed that lower doses of this chemical could affect negatively 
(a)

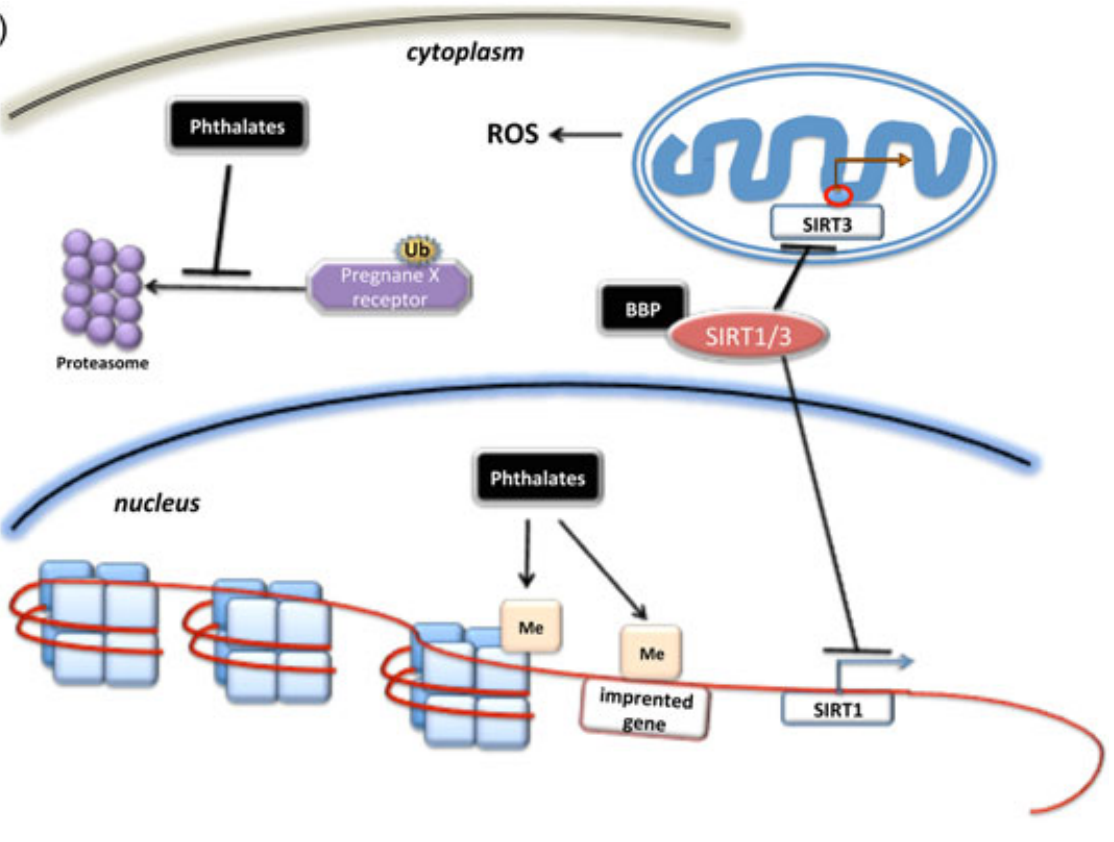

(b)

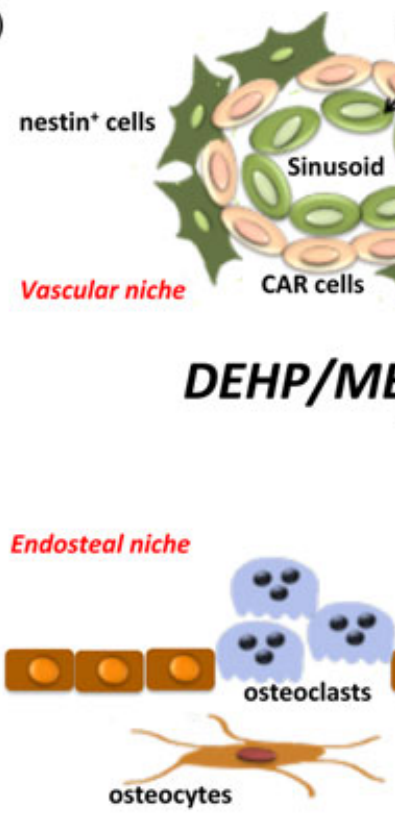

Endothelial Cells
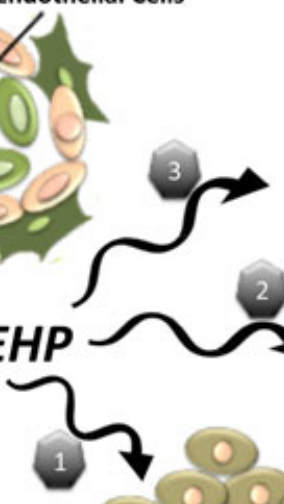

osteoblasts

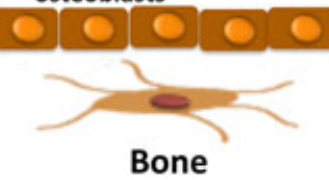

FIGURE 4 Effects of phthalates outcomes on bone and bone marrow cell populations. (a) Phthalates disrupt the proteasome degradation of the nuclear pregnane $X$ receptor and imbalance steroid hormone release. BBP binds to SIRT1 and SIRT3, decreasing their expression levels and consequently the (i) expression of two SIRT-dependent mitochondrial biogenesis genes and (ii) ROS production. (b) MEHP diverts the osteogenic MSCs commitment toward adipogenesis (1). DEHP and MEHP exposure inhibits proliferation and induces apoptosis in developing B cells (2) affecting the HSC operational schedule (3). BBP, benzyl butyl phthalate; DEHP, di(2-ethylhexyl)phthalate; HSC, hematopoietic stem cell; MEHP, mono(2-ethylhexyl)phthalate; MSC, mesenchymal stem cell; ROS, reactive oxygen species; SIRT, sirtuin [Color figure can be viewed at wileyonlinelibrary.com] femoral geometry and bone strength. Indeed, the administration of DES via a min-osmotic pump in the dam at doses of $0.1 \mathrm{~g} \cdot \mathrm{kg}^{-1} \cdot \mathrm{day}^{-1}$ from gestation day 11 and to the pups until postnatal day 12 generated peculiar outcomes. Although femur length was increased in both the female and the male DES-exposed group, marrow cavity diameter, cortical width and bone tensile strength were decreased. As a consequence, the increase in length with a concurrent decrease in material strength generates fragile bones with increased cortical porosity and altered mineral composition (Pelch et al., 2012). Nonetheless, DES exposure $\left(10 \mathrm{~g} \cdot \mathrm{kg}^{-1} \cdot \mathrm{day}^{-1}\right)$ during gestation days 11-14 increased lumbar and femoral bone area, trabecular area and bone mineral content, only in female offspring. Male DES-treated mice developed a pathological tableau and therefore a decrease in all the above-mentioned structural-anatomical parameters (Rowas et al., 2012), once more highlighting the sex-related effects of DES.

An interesting study by S. E. Lin, Huang, Wu, Wu and Cui (2013) in ovariectomized (OVX) rats revealed that the administration of DES $\left(10 \mu \mathrm{g} \cdot \mathrm{kg}^{-1} \cdot \mathrm{day}^{-1}\right)$ plus aspirin $\left(9 \mathrm{mg} \cdot \mathrm{kg}^{-1} \cdot \mathrm{day}^{-1}\right)$ via an oral gavage for 90 days can effectively prevent bone loss by reducing bone resorption and can prevent hypertriglyceridemia with beneficial effects on lipid metabolism in OVX rats. Therefore, the authors reported that combined aspirin and low-dose DES could be a promising therapeutic platform against postmenopausal bone loss. 


\section{6 | Organotin compounds}

Organotin compounds are environmental contaminants used as marine antifouling agents and to date, have been used in food crop fungicides, wood preservatives, and stabilizers for polyvinylchloride polymers. Accumulation of these compounds has been reported in marine fish and mammals (Harino, Fukushima \& Kawai, 2000; Kannan, Corsolini, Focardi, Tanabe \& Tatsukawa, 1996), but also in human liver and blood at concentrations ranging from 0.1 to $450 \mathrm{nM}$ (Antizar-Ladislao, 2008). Their ability to be ubiquitous was further confirmed by the fact that these chemicals have been found in measurable quantities in house dust (Cornelissen et al., 2008; Kannan, Takahashi, Fujiwara, Mizukawa, \& Tanabe, 2010). The organotin compounds were also considered environmental obesogens due to their ability to disrupt the homeostatic control of adipogenesis and consequently to interfere with bone marrow MSCs commitment to osteoblast and bone cell deposition.

Different experimental protocols have been used to investigate the adverse effects of organotin compounds on bone and bone marrow anatomical compartments.

For instance, the administration of TBT to pregnant rats via a gavage (10 or $20 \mathrm{mg} / \mathrm{kg}$ ) from gestational day $0-19$, induced delayed ossification of the fetal skeleton accompanied by misaligned sternebrae or sternoschisis (Adeeko et al., 2003). These findings were further supported by other reports, showing that TBT subcutaneous administration $(1 \mathrm{mg} / \mathrm{kg}$ ) to pregnant mice at days 10, 12 and 14, compromised supraoccipital bone calcification of fetuses and, in some cases, metatarsal and metacarpal ossification (Tsukamoto, Ishihara, Miyagawa-Tomita \& Hagiwara, 2004). For a better understanding of the osteodestructive effects of TBT at the molecular level, in vitro experiments were performed in rat calvarial osteoblastic (ROB) cells. It is noteworthy that TBT $\left(10^{-8}\right.$ and $\left.10^{-7} \mathrm{M}\right)$ treatment on ROB cells suppressed the expression of key players of bone formation, such as ALP and osteocalcin, and impeded calcium signaling and deposition (Tsukamoto et al., 2004).

It is noteworthy that other in vitro studies have shed light on the effects of TBT on human and mouse bone marrow MSCs and their differentiation schedule. TBT treatment at doses of 5 or $50 \mathrm{nM}$ (human MSCs) and $50 \mathrm{nM}$ (mouse MSCs) reprogrammed the fate of MSCs to favor adipogenesis via activation of PPAR $\gamma$ signaling at the expense of the osteogenic signaling cascades (Kirchner, Kieu, Chow, Casey \& Blumberg, 2010). Recently, it has been found that TBT pretreatment in mice MSCs (doses of 5 and $50 \mathrm{nM}$ ) for $48 \mathrm{hr}$ upregulated the adipose commitment marker zinc finger protein 423 (Zfp423), the early differentiation markers PPAR $\gamma$ and CCAAT-enhancer-binding protein $\alpha$ (Cebpa), and the adipose lineage markers such as fatty acid-binding protein 4 (Fabp4), fat-specific protein 27 (Fsp27), and lipoprotein lipase (Lpl). These observations confirm the transcriptional regulation of early adipogenic markers by TBT, RXR-mediated (Shoucri et al., 2017).

The above-mentioned in vitro findings on the effects of TBT on MSCs homeostasis were reproduced to in vivo evidences. Pregnant dams were administered TBT $(0.1 \mathrm{mg} / \mathrm{kg})$ by gavage and at 8 weeks postpartum, the bone marrow MSCs were isolated from the offspring. As expected, the stromal stem cells exhibited a decreased osteogenic capacity and augmented adipogenic differentiation and adipocyte population (Kirchner et al., 2010). Recent reports have supported the findings presented so far and claimed that TBT $(100 \mathrm{nM})$ and triphenyltin (TPhT; $50 \mathrm{nM})$ treatment in mouse bone marrow cultures for 7 days caused osteogenic lineage suppression and an increase in proadipogenic markers increase (Watt \& Schlezinger, 2015). The molecular explanation for the antiosteogenic organotin action is based on the interaction of the chemicals with both PPAR $\gamma$ and RXRs, suggesting their direct roles in multiple NR pathways. The direct organotin activation of PPAR $\gamma$ and RXR switches the MSCs schedule versus adipogenesis instead of osteoblast differentiation and bone deposition (Baker, Watt, Huang, Gerstenfeld \& Schlezinger, 2015). It is noteworthy that prenatal TBT exposure $(5.42,54.2$ or $542 \mathrm{nM}$ ) to pregnant mice induced a transgenerational reprogramming of MSC fate due to decreased expressiona of bone-specific markers, such as ALP and Runx2, in female mice 1 (F1) and F3 generations. In parallel, an increase of adipogenic signals and the MSC swift toward adipogenic lineage at the expense of the osteogenic lineage were observed even upto the F3 generation (Chamorro-García et al., 2013). Considering that lymphopoiesis is supported by bone marrow stromal elements and MSC disruption drives impaired hematopoiesis (Agas et al., 2015) recent studies showed that TBT $(80-100 \mathrm{nM})$, on the one hand, compromises the morphological and functional aspects of the bone marrow niches, and on the other, suppresses the proliferation of hematopoietic cells in an ex vivo mice bone marrow model. Indeed, TBT exposure in mice reduced the progression of $B$ cells from the early pro- $B$ to the pre- $B$ stage, which may be related to a reduction in "aging-sensitive" B cells within the bone marrow (Baker et al., 2017). The overall bone marrow DES targets are shown in Figure 5.

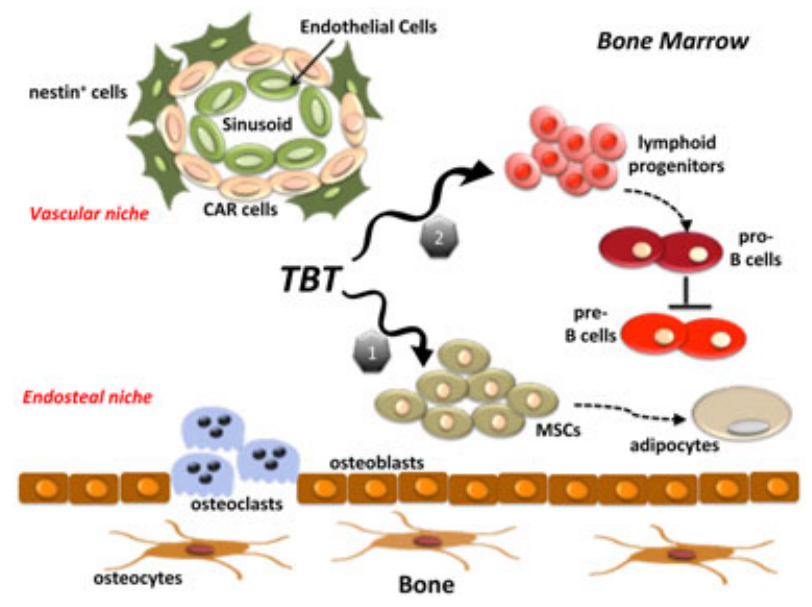

FIGURE 5 Effects of organotin compounds on bone marrow MSCs and HSCs. TBT influences the fate of MSCs to favor adipogenesis (1). TBT reduces the progression of $B$ cells from the early pro-B to the pre-B stage (2). HSC, hematopoietic stem cell; MSC, mesenchymal stem cell; TBT, tributyltin [Color figure can be viewed at wileyonlinelibrary.com] 


\section{7 | Dioxin and dioxin-like compounds}

It is been a while since research has attributed endocrine disrupting properties to dioxin and its derivatives as they can bind to AhRs and modify the cell transcriptional machinery (Singh et al., 2000). This class of environmental contaminants has been considered ubiquitous, found in cigarette smoke and herbicides but also in the food chain, principally in meat, fatty milk, and fish products. Dioxins can be released from natural sources such as forest fires and volcanoes. A peculiar characteristic of these chemicals is their ability to be transferred from adipose tissue to the mother's milk and consequently move on to the child about $20-25 \%$ of mother's dioxin burden (Kvalem et al., 2012; Tuomisto, 2001). Due to their lipophilic nature they are found in many human tissues and described as immunotoxicants, neurotoxicants, hepatoxicants and inducers of metabolic disorders, wasting syndromes and developmental alterations in experimental animal models (Pohjanvirta \& Tuomisto, 1994). Thus, dioxin derivatives have been considered highly toxic and stable compounds and it has been estimated that in the mid-1990s, the daily intake of polychlorinated dibenzo-p-dioxins (PCDDs), PCDFs, and $\mathrm{PCBs}$ by humans approached values of $1-3 \mathrm{pg}$ toxic equivalent quantity per kg body weight per day (World Health Organization, 1996). Current reports have confirmed that children living near electronic waste recycling facilities in China, are exposed to a range of dioxin derivatives daily (Guangen et al., 2011; Leung et al., 2011; Shen et al., 2010).

Considering that (i) the prenatal and perinatal periods of development are particularly susceptible to the effects of toxicants and (ii) the severity of health outcomes is dependent on the developmental time period during which exposure to toxicants occurs, several reports have argued that the major adverse effects of dioxin are exerted in the growth-related period (Birnbaum, 1995; Damstra, 2002).

In this vein, various severe bone and bone marrow morphological modifications have been diagnosed after dioxin exposure in utero or at the early postnatal stage.

The influence of TCDD on bone cells metabolism has been studied for more than three decades. TCDD is considered the most potent dioxin derivative, with direct cytotoxic effects via the activation of AhR cascade and the transcription of dioxin-responsive genes (Okey, 2007). Keeping in mind that both osteoblasts and osteoclasts express $A h R$, with receptor transduction peaking after matrix maturation and during the osteoblast late differentiation stage, the close correlation between the action of TCDD and bone cell metabolism is clear. The in vitro findings on rat osteoblastic cultures TCDD-treated $\left(10^{-8} \mathrm{M}\right)$ strongly buttress the above consideration. In fact, TCDD suppressed postconfluent formation of multicellular nodules and thus the osteoblast maturation process (Gierthy, Silkworth, Tassinari, Stein \& Lian, 1994). Comparable results were also obtained when rat bone marrow stromal cells were exposed to TCDD $\left(10^{-9}\right.$ to $\left.10^{-12} \mathrm{M}\right)$. The main osteodifferentiating markers, such as ALP and collagen type I, were reduced after the administration of TCDD at values 33 and $30 \%$ correspondingly (Singh et al., 2000). Osteocalcin and Runx2 expressions were also decreased in mouse and rat bone marrow stromal cell cultures treated with TCDD (100 fM or $10 \mathrm{pM}$; Korkalainen et al., 2009).

Several experiments have been carried out to highlight effects of AhR signaling in developmental bone formation TCDD-exposed. In vivo findings in rats suggest that TCDD-AhR interactions cause anatomical changes, especially effects on tibial length, cortical density, and diaphyseal geometry (TCDD doses of 1.7 or $17 \mathrm{~g} / \mathrm{kg}$ for 20 days; Jamsa et al., 2001). There is no doubt that these chemicals trigger skeletal defects according to different administration protocols (e.g. TCDD doses of 5 or $10 \mathrm{nM}$; Ryan et al., 2007).

Nonetheless, during the gestational and postnatal period TCDD exposure in rats resulted in decreased cross-sectional area of the tibia and the femur accompanied by a smaller endosteal and periosteal circumference (TCDD doses of $1 \mathrm{~g} / \mathrm{kg}$ from gestational day 11 to postnatal day 19; Miettinen et al., 2005). Interestingly, administration of TCDD $1 \mathrm{~g} / \mathrm{kg}$ on gestational day 11 reduced the bending force of the tibia, and caused bone stiffness, and alterations in hardness, plasticity index, and storage modulus (Finnila et al., 2010). These results clearly indicate the harmful effects of dioxin on bone integrity. TCDD treatment rendered the skeleton more ductile, softer and less able to store energy.

Recent findings have demonstrated that the timing and the duration of TCDD exposure exerts differential effect on craniofacial development and growth in rodents, including craniofacial size reduction and altered craniofacial geometric morphometrics such as suture morphology and fluctuating asymmetry. Definitely, TCDD-induced bone disruption occurs at a lower dose of exposure during utero-lactational and growth stages than during adulthood (Sholts et al., 2015).

It is well established that activation of the AhR by dioxin leads to the disruption of intracellular molecular pathways, with direct effects on bone metabolism. Specifically, TCDD inhibits the action of BMP2 on bone regeneration and spine fusion in a rat arthrodesis model, predicted a disruption of specific key role osteoforming signaling cascades (Hsu et al., 2015).

Other dioxin-like compounds such as 3-MC, B $\alpha \mathrm{P}$ and $\mathrm{PCBs}$ can also exert analogous effects on bone. For instance, 3-MC $1 \mathrm{mg} / \mathrm{kg}$ administration in pregnant mice triggered offspring delayed ossification of sternebrae, limbs, cervical thoracic and lumbar vertebrae and sopraoccipital bone in the offspring. The adverse 3-MC effects on skeletal development were due to AhR signals, which resulted in the disruption of specific genes disruption involved in bone formation (Naruse et al., 2004; Naruse, Ishihara, Miyagawa-Tomita, Koyama, \& Hagiwara, 2002). In terms of the action of $\mathrm{B} \alpha \mathrm{P}$ on bone, there are mostly in vitro reports indicating that this polycyclic aromatic hydrocarbon can induce abnormal osteoblast proliferation, decreased osteoclast activity and accelerated chondrocyte differentiation in rodents (Kung, Yukata, O'Keefe \& Zuscik, 2012; Tsai et al., 2004; Voronov, Li, Tenenbaum \& Manolson, 2008). The above-mentioned findings indicate a doubtless pathological tableau and highlight the impaired bone cell metabolic features that occur after $\mathrm{B} \alpha \mathrm{P}$ treatment. 
The halogenated aromatic hydrocarbon PCB has been considered a potent xenoestrogen. On administration at an overall dose of $384 \mathrm{~g} / \mathrm{kg}$ in adult female rats, $\mathrm{B} \alpha \mathrm{P}$ induced significant alterations in vertebral mineral composition and stimulated bone resorption at the expense of bone deposition (Alvarez-Lloret, Lind, Nyberg, ÖrbergOrberg \& Rodríguez-Navarro, 2009).
Recently, AhR signaling has been associated with the maintenance and differentiation of adult HSCs (Lindsey \& Papoutsakis, 2012; B. W. Smith et al., 2013). Hematopoiesis is widely acknowledged as the process by which immature HSCs and progenitor cells differentiate into mature blood and immune cells (Agas et al., 2015; Sabbieti, Marchetti, Censi, Lacava \& Agas, 2017). HSC niches within

(a)

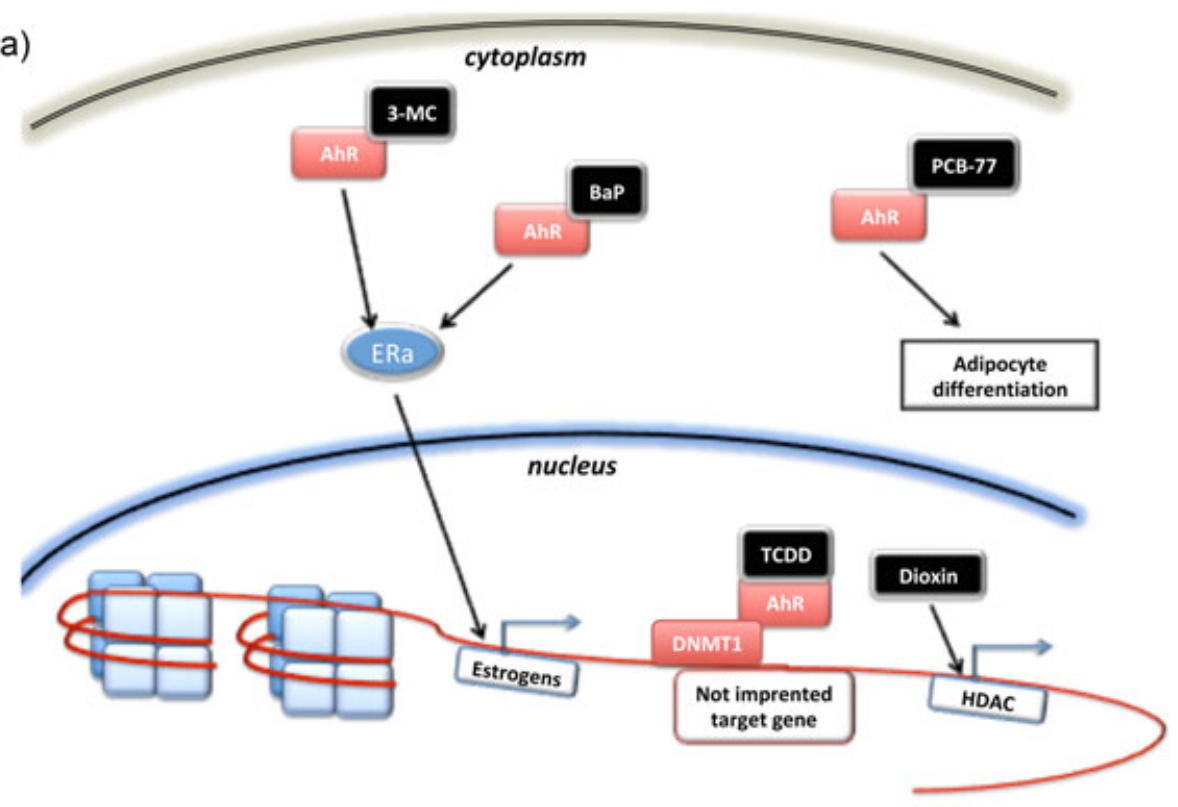

(b)

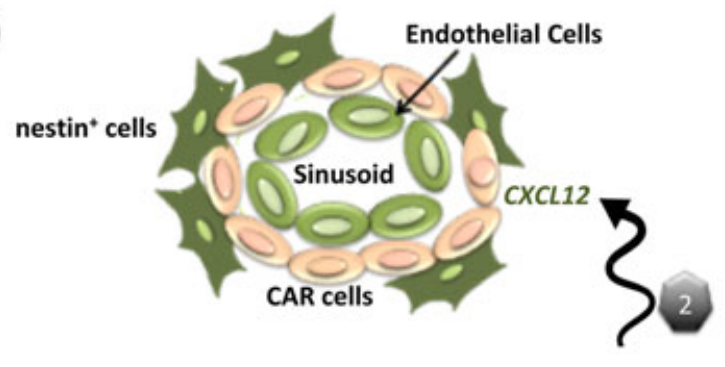

\section{Bone Marrow}

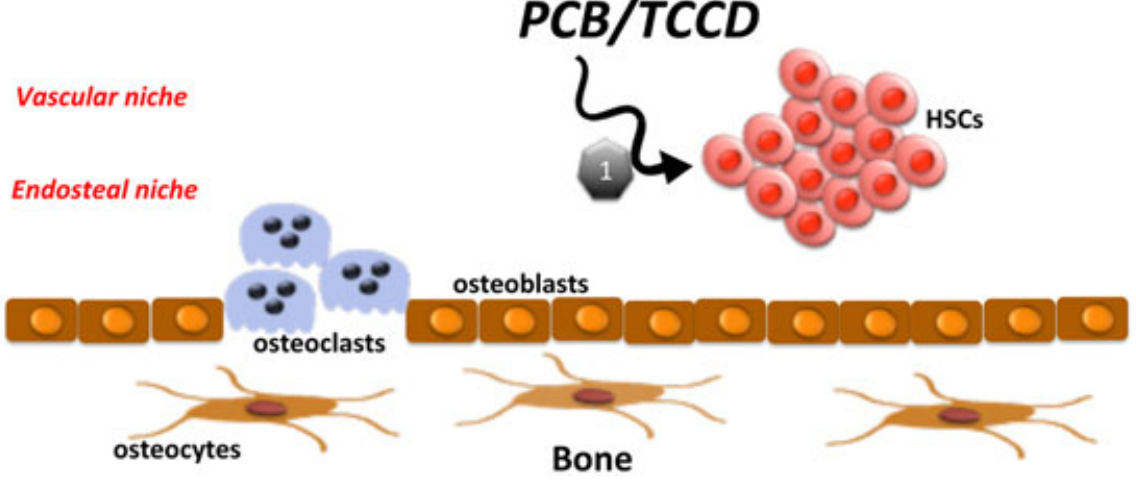

PCB/TCCD

FIGURE 6 Dioxin compounds induce epigenetic modifications and alter bone marrow physiology. (a) B $\alpha \mathrm{P}, 3-\mathrm{MC}$ and PCB-77 by disrupting the AhR signaling network activate ER- $\alpha$ and induce estrogen transcription and higher estradiol production stimulates adipocyte differentiation. TCDD recruits DNMT1 on the target gene site via interaction with AhR and causes gene-specific modifications in the methylation status.

(b) PCB and TCDD lead to enfeebled hematopoiesis (1) and reduce CXCR4-CXCL12 expression (2). AhR, aryl hydrocarbon receptor; B $\alpha$ P, benzo $[\alpha]$ pyrene; DNMT, DNA methyltransferase; ER, estrogen receptor; HDAC, histone deacetylase; HSC, hematopoietic stem cell; 3-MC, 3-methylcholanthrene; TCDD, 2,3,7,8-tetrachlorodibenzo-p-dioxin [Color figure can be viewed at wileyonlinelibrary.com] 
TABLE 1 Effects of EDCs on bone and bone marrow cells

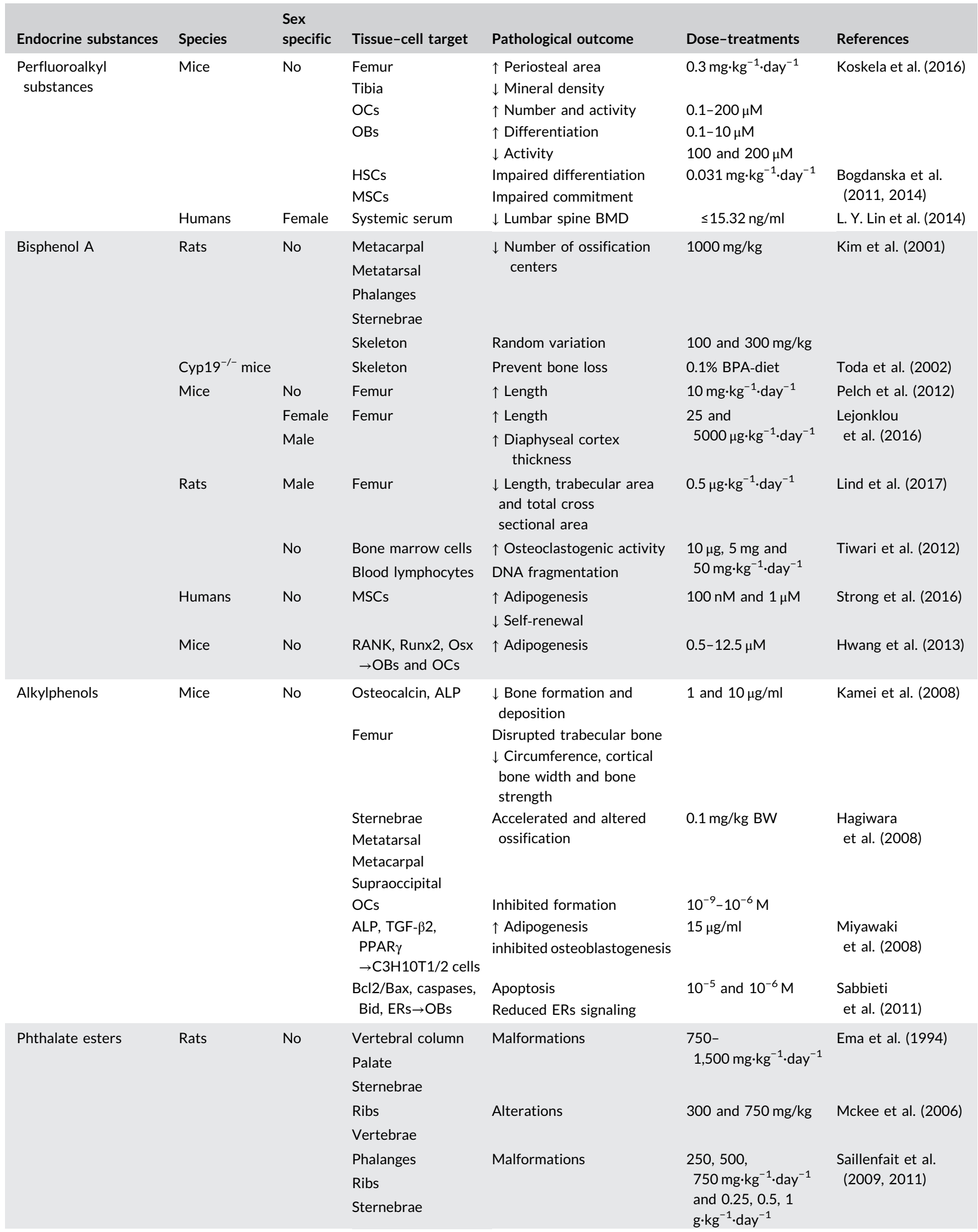


TABLE 1 (Continued)

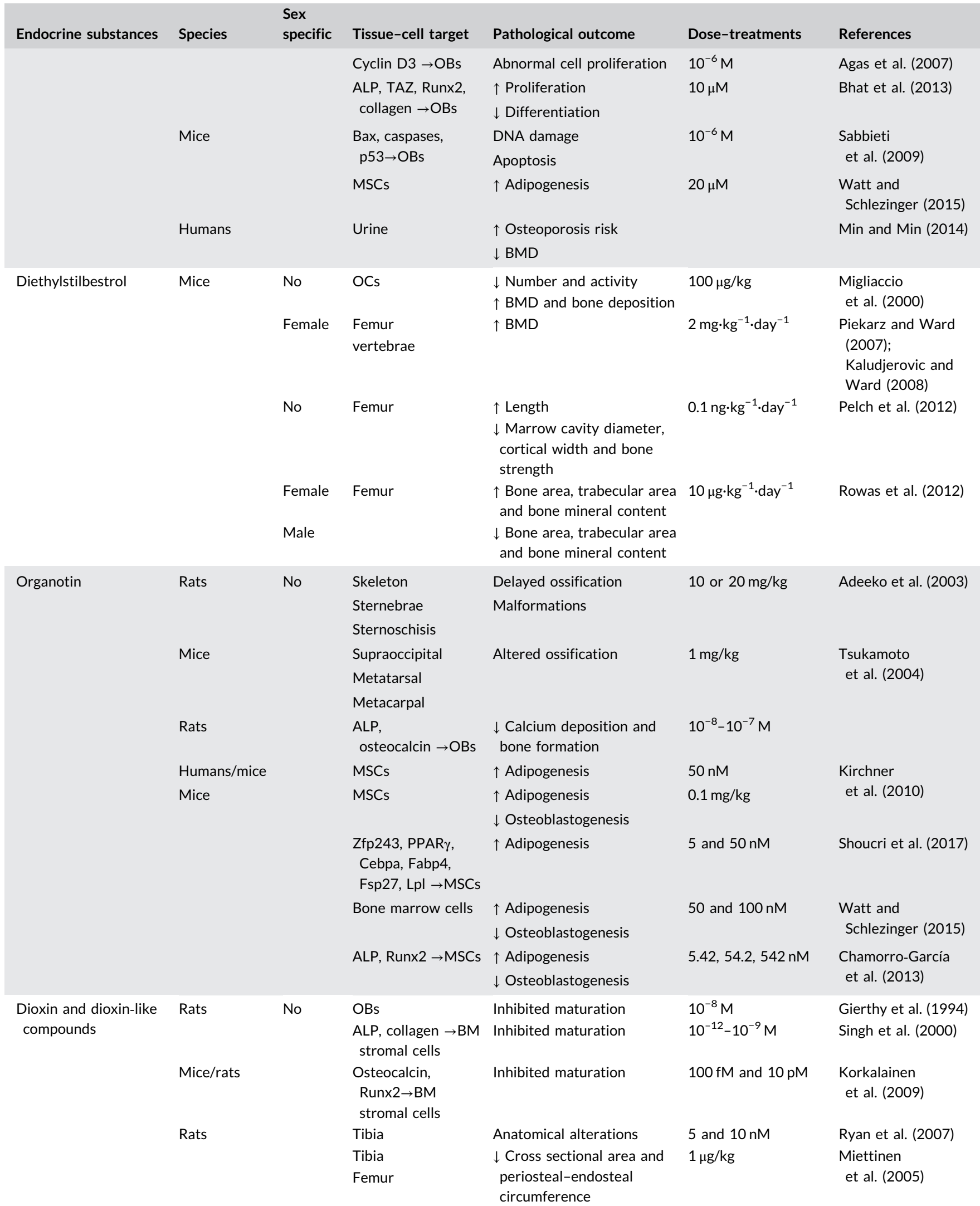


TABLE 1 (Continued)

\begin{tabular}{|c|c|c|c|c|c|c|}
\hline Endocrine substances & Species & $\begin{array}{l}\text { Sex } \\
\text { specific }\end{array}$ & Tissue-cell target & Pathological outcome & Dose-treatments & References \\
\hline & & & Tibia & $\begin{array}{l}\downarrow \text { Bending force and bone } \\
\text { stiffness }\end{array}$ & $1 \mu \mathrm{g} / \mathrm{kg}$ & Finnila et al. (2010) \\
\hline & Mice & & Skeleton & Delayed ossification & $1 \mathrm{mg} / \mathrm{kg}$ & $\begin{array}{l}\text { Naruse et al. } \\
\text { (2002; 2004) }\end{array}$ \\
\hline & Rats & & Vertebrae & $\begin{array}{l}\text { Altered mineral composition } \\
\uparrow \text { Bone resorption }\end{array}$ & $384 \mu \mathrm{g} / \mathrm{kg}$ & $\begin{array}{l}\text { Alvarez-Lloret } \\
\text { et al. (2009) }\end{array}$ \\
\hline
\end{tabular}

ALP, alkaline phosphatase; Bax, bcl-2-like protein 4; Bcl2, B-cell lymphoma 2; Bid, BH3-interacting domain death agonist; BMD, bone mineral density; BPA, bisphenol A; Cebpa, CCAAT-enhancer-binding protein $\alpha$; EDC, endocrine-disrupting chemical; ER, estrogen receptor; Fabp4, fatty acid-binding protein 4; Fsp27, fat-specific protein 27; HSC, hematopoietic stem cell; Lpl, lipoprotein lipase; MSC, mesenchymal stem cell; OBs, osteoblasts; OCs, osteoclasts; PPAR $\gamma$, peroxisome proliferation-activated receptor $\gamma$; Runx2, Runt-related transcription factor 2 ; TGF- $\beta 2$, transforming growth factor $\beta 2$; Zfp423, zinc finger protein 423.

the bone marrow confines contain long-term self-renewal and multipotent lineages. In response to environmental signals, a percentage of the long-term HSCs undergoes differentiation and initiates maturation of more specific effector cells (Luc, Buza-Vidas \& Jacobsen, 2008). Notably, mice developmentally exposed to TCDD, the most potent agonist of the AhR, displayed persistent immune defects (Mustafa et al., 2008), and fetal immature hematopoietic stem and progenitor cells showed decreased ability to complete normal hematopoietic differentiation (Stein \& Baldwin, 2013). It is worth pointing out that the bone marrow regulatory activities, comprising HSC and MSC incubation and maturation, have to deal with the interdependence of the defined bone marrow niche elements (Agas et al., 2015; Agas, Marchetti, Hurley \& Sabbieti, 2013; Sabbieti et al., 2017). Disruption of the functionality of even one of these elements, such as the activation of AhR signaling by dioxin compounds, can lead to severe local or systemic pathological conditions, such as enfeebled hematopoiesis. Recently, in vitro findings have supported the above result, revealing that PCB- and TCDD-treated rat MSCs displayed reduced CXCR4-CXCL12 expression (J. T. Smith, Schneider, Katchko, Yun \& Hsu, 2017). Considering the main role of these two chemokines in bone marrow homeostatic features such as HSC retention and chemotaxis, osteoblastogenesis and osteoclastogenesis, it may be assumed that dioxin compounds induce considerable modifications at the bone marrow level. Dioxin and dioxin-like compounds epigenetic targets as well as bone marrow dioxin-induced modifications are shown in Figure 6.

In terms of human health, the NHANES database has specified that PCBs are strongly associated with type 2 diabetes, whereas PCDDs and PCDFs are weakly linked to minor metabolic disorders (Lee, Lee, Steffes \& Jacobs, 2007). Currently, extensive investigation is underway on the action of dioxin and its bone and bone marrow targets in humans.

\section{4 | CONCLUSION}

Considerable evidence shows that maternal and early childhood exposure to environmental contaminants leads to modifications in hormone production, bone homeostasis and bone marrow microhabitats. The endocrine-disrupting compounds exert their action by the modulating a plethora of cellular receptors, such as aryl hydrocarbon, NR and ERs, and consequently affect the intracellular signaling cascades and transcriptional activity. For instance, AhR-EDC interactions can regulate key player genes involved in morphogenesis, survival and patterning of the bone tissue in the development and maintenance stages. Moreover, the demonstration that EDCs can interfere with the bone marrow reservoir and swift the fate of the stem-progenitor cell population has opened up new avenues for understanding the biochemical and molecular platforms used by EDCs (the overall EDCs targets are reported in Table 1). Therefore, in the last decade, substantial efforts have been made by the scientific community to deepen and understand the complex mechanisms of the xenoestrogen mode of action and different transgenic or knockout animal models have been used for this scope. On the other hand, there are still few studies on the adverse effects of EDCs on the human endocrine system and bone homeostasis. Providing more information and relations between EDCs-exposed animals and humans remains a compelling task to address further researches.

\section{CONFLICTS OF INTEREST}

The authors declare that there are no conflicts of interest.

\section{ORCID}

Dimitrios Agas (D) http://orcid.org/0000-0002-7809-3601

\section{REFERENCES}

Acconcia, F., Fiocchetti, M., \& Marino, M. (2017). Xenoestrogen regulation of ER $\alpha / E R \beta$ balance in hormone-associated cancers. Molecular and Cellular Endocrinology, 457, 3-12.

Adeeko, A., Li, D., Forsyth, D. S., Casey, V., Cooke, G. M., Barthelemy, J., ... Hales, B. F. (2003). Effects of in utero tributyltin chloride exposure in the rat on pregnancy outcome. Toxicological Sciences, 74, 407-415.

Agarwal, D. K., Maronpot, R. R., Lamb, J. C., \& Kluwe, W. M. (1985). Adverse effects of butyl benzyl phthalate on the reproductive and hematopoietic systems of male rats. Toxicology, 35, 189-206.

Agas, D., Marchetti, L., Capitani, M., \& Sabbieti, M. G. (2013). The dual face of parathyroid hormone and prostaglandins in the osteoimmune system. American Journal of Physiology, Endocrinology and Metabolism, 305, E1185-E1194. 
Agas, D., Marchetti, L., Douni, E., \& Sabbieti, M. G. (2015). The unbearable lightness of bone marrow homeostasis. Cytokine and Growth Factor Reviews, 26, 347-359.

Agas, D., Marchetti, L., Hurley, M. M., \& Sabbieti, M. G. (2013). Prostaglandin F2 $\alpha$ : A bone remodeling mediator. Journal of Cellular Physiology, 228, 2149-2158.

Agas, D., Sabbieti, M. G., Capacchietti, M., Materazzi, S., Menghi, G., Materazzi, G., ... Marchetti, L. (2007). Benzyl butyl phthalate influences actin distribution and cell proliferation in rat Py1a osteoblasts. Journal of Cellular Biochemistry, 101, 543-551.

Agas, D., Sabbieti, M. G., \& Marchetti, L. (2013). Endocrine disruptors and bone metabolism. Archives of Toxicology, 4, 735-751.

Alvarez-Lloret, P., Lind, P. M., Nyberg, I., Örberg, J., \& RodríguezNavarro, A. B. (2009). Effects of 3,3',4,4',5-pentachlorobiphenyl (PCB126) on vertebral bone mineralization and on thyroxin and vitamin D levels in Sprague-Dawley rats. Toxicology Letters, 187, 63-68.

Annab, L. A., Bortner, C. D., Sifre, M. I., Collins, J. M., Shah, R. R., Dixon, D., ... Archer, T. K. (2012). Differential responses to retinoic acid and endocrine disruptor compounds of subpopulations within human embryonic stem cell lines. Differentiation, 84, 330-343.

Antizar-Ladislao, B. (2008). Environmental levels, toxicity and human exposure to tributyltin (TBT)-contaminated marine environment. A review. Environment International, 34, 292-308.

Anway, M. D., \& Skinner, M. K. (2006). Epigenetic transgenerational actions of endocrine disruptors. Endocrinology, 147, S43-S49.

Arcaro, K. F., O'Keefe, P. W., Yang, Y., Clayton, W., \& Gierthy, J. F. (1999). Antiestrogenicity of environmental polycyclic aromatic hydrocarbons in human breast cancer cells. Toxicology, 133, 115-127.

Arsenescu, V., Arsenescu, R. I., King, V., Swanson, H., \& Cassis, L. A. (2008). Polychlorinated biphenyl-77 induces adipocyte differentiation and proinflammatory adipokines and promotes obesity and atherosclerosis. Environmental Health Perspectives, 116, 761-768.

Baker, A. H., Watt, J., Huang, C. K., Gerstenfeld, L. C., \& Schlezinger, J. J. (2015). Tributyltin engages multiple nuclear receptor pathways and suppresses osteogenesis in bone marrow multipotent stromal cells. Chemical Research in Toxicology, 28, 1156-1166.

Baker, A. H., Wu, T. H., Bolt, A. M., Gerstenfeld, L. C., Mann, K. K., \& Schlezinger, J. J. (2017). From the Cover: Tributyltin alters the bone marrow microenvironment and suppresses B cell development. Toxicological Sciences, 158, 63-75.

Barlas, N., \& Aydoğan, M. (2009). Histopathologic effects of maternal 4-tert-octylphenol exposure on liver, kidney and spleen of rats at adulthood. Archives of Toxicology, 83, 341-349.

Bateman, M. E., Strong, A. L., McLachlan, J. A., Burow, M. E., \& Bunnell, B. A. (2017). The effects of endocrine disruptors on adipogenesis and osteogenesis in mesenchymal stem cells: A review. Frontiers in Endocrinology, 7, 171.

Benjamin, S., Masai, E., Kamimura, N., Takahashi, K., Anderson, R. C., \& Faisal, P. A. (2017). Phthalates impact human health: Epidemiological evidences and plausible mechanism of action. Journal of Hazardous Materials, 340, 360-383.

Bhat, F. A., Ramajayam, G., Parameswari, S., Vignesh, R. C., Karthikeyan, S., Senthilkumar, K., ... Srinivasan, N. (2013). Di 2-ethyl hexyl phthalate affects differentiation and matrix mineralization of rat calvarial osteoblasts in vitro. Toxicology In Vitro, 27, 250-256.

Birnbaum, L. S. (1995). Developmental effects of dioxins and related endocrine disrupting chemicals. Toxicology Letters, 82-83, 734-750.

Blount, B. C., Silva, M. J., Caudill, S. P., Needham, L. L., Pirkle, J. L., Sampson, E. J., ... Brock, J. W. (2000). Levels of seven urinary phthalate metabolites in a human reference population. Environmental Health Perspectives, 108, 979-982.

Bogdanska, J., Borg, D., Sundström, M., Bergström, U., Halldin, K., Abedi-Valugerdi, M., ... Nobel, S. (2011). Tissue distribution of 35Slabelled perfluorooctanoic sulfonate in adult mice after oral exposure to a low environmentally relevant dose or a high experimental dose. Toxicology, 284, 54-62.

Bogdanska, J., Sundström, M., Bergström, U., Borg, D., Abedi-Valugerdi, M., Bergman, A., DePierre, J., \& Nobel, S. (2014). Tissue distribution of 35S-labelled perfluorobutanesulfonic acid in adult mice following dietary exposure for 1-5 days. Chemosphere, 98, 28-36.

Bonefeld-Jørgensen, E. C., Long, M., Hofmeister, M. V., \& Vinggaard, A. M. (2007). Endocrine-disrupting potential of bisphenol A, bisphenol A dimethacrylate, 4-n-nonylphenol, and 4-n-octylphenol in vitro: New data and a brief review. Environmental Health Perspectives, 115(Suppl 1), 69-76.

Chamorro-García, R., Sahu, M., Abbey, R. J., Laude, J., Pham, N., \& Blumberg, B. (2013). Transgenerational inheritance of increased fat depot size, stem cell reprogramming, and hepatic steatosis elicited by prenatal exposure to the obesogen tributyltin in mice. Environmental Health Perspectives, 121, 359-366.

Cornelissen, G., Pettersen, A., Nesse, E., Eek, E., Helland, A., \& Breedveld, G. D. (2008). The contribution of urban runoff to organic contaminant levels in harbour sediments near two Norwegian cities. Marine Pollution Bulletin, 56, 565-573.

De Coster, S., \& van Larebeke, N. (2012). Endocrine-disrupting chemicals: Associated disorders and mechanisms of action. Journal of Environmental and Public Health, 2012. 713696-52

Cui, L., Zhou, Q., Liao, C., Fu, J., \& Jiang, G. (2009). Studies on the toxicological effects of PFOA and PFOS on rats using histological observation and chemical analysis. Archives of Environmental Contamination and Toxicology, 56, 338-349.

Damstra, T. (2002). Potential effects of certain persistent organic pollutants and endocrine disrupting chemicals on the health of children. Journal of Toxicology. Clinical Toxicology, 40, 457-465.

DeFlorio-Barker, S. A., \& Turyk, M. E. (2016). Associations between bone mineral density and urinary phthalate metabolites among postmenopausal women: A cross-sectional study of NHANES data 2005-2010. International Journal of Environmental Health Research, 26, 326-345.

Ema, M., Amano, H., \& Ogawa, Y. (1994). Characterization of the developmental toxicity of di-n-butyl phthalate in rats. Toxicology, 86, 163-174.

Ema, M., Itami, T., \& Kawasaki, H. (1992). Embryolethality andnteratogenicity of butyl benzyl phthalate in rats. Journal of Applied Toxicology, 12, 179-183.

Ema, M., Itami, T., \& Kawasaki, H. (1993). Teratogenic phase specificity of butyl benzyl phthalate in rats. Toxicology, 79, 11-19.

European Food Safety Authority (2015). Scientific Opinion on the risks to public health related to the presence of bisphenol A (BPA) in foodstuffs. EFSA Journal, 13, 3978.

Fierens, S., Mairesse, H., Heilier, J., De Burbure, C., Focant, J., Eppe, G., ... Bernard, A. (2003). Dioxin/polychlorinated biphenyl body burden, diabetes and endometriosis: Findings in a population-based study in Belgium. Biomarkers, 8, 529-534.

Finnila, M. A., Zioupos, P., Herlin, M., Miettinen, H. M., Simanainen, U., Hakansson, H., ... Jamsa, T. (2010). Effects of 2,3,7,8-tetrachlorodibenzo-p-dioxin exposure on bone material properties. Journal of Biomechanics, 43, 1097-1103.

Fisher, M., Arbuckle, T. E., Wade, M., \& Haines, D. A. (2013). Do perfluoroalkyl substances affect metabolic function and plasma lipids? -Analysis of the 2007-2009, Canadian Health Measures Survey (CHMS) Cycle 1. Environmental Research, 121, 95-103.

Flöter, V. L., Galateanu, G., Fürst, R. W., Seidlová-Wuttke, D., Wuttke, W., Möstl, E., ... Ulbrich, S. E. (2016). Sex-specific effects of low-dose gestational estradiol-17 $\beta$ exposure on bone development in porcine offspring. Toxicology, 366-367, 60-67.

Fromme, H., Tittlemier, S. A., Völkel, W., Wilhelm, M., \& Twardella, D. (2009). Perfluorinated compounds-exposure assessment for the general population in Western countries. International Journal of Hygiene and Environmental Health, 212, 239-270. 
Fujita, M., Urano, T., Horie, K., Ikeda, K., Tsukui, T., Fukuoka, H., ... Inoue, S. (2002). Estrogen activates cyclin-dependent kinases 4 and 6 through induction of cyclin D in rat primary osteoblasts. Biochemical and Biophysical Research Communications, 299, 222-228.

Fukumoto, S., \& Martin, T. J. (2009). Bone as an endocrine organ. Trends in Endocrinology and Metabolism, 20, 230-236.

Geens, T., Aerts, D., Berthot, C., Bourguignon, J. P., Goeyens, L., Lecomte, P., ... Covaci, A. (2012). A review of dietary and non-dietary exposure to bisphenol-A. Food and Chemical Toxicology, 50, 3725-3740.

Gierthy, J. F., Silkworth, J. B., Tassinari, M., Stein, G. S., \& Lian, J. B. (1994). 2,3,7,8-Tetrachlorodibenzo-p-dioxin inhibits differentiation of normal diploid rat osteoblasts in vitro. Journal of Cellular Biochemistry, 54, 231-238.

Giger, W., Brunner, P., \& Schaffner, C. (1984). 4-Nonylphenol in sewage sludge: Accumulation of toxic metabolites from nonionic surfactants. Science, 225, 623-625.

Gore, A. C., Heindel, J. J., \& Zoeller, R. T. (2006). Endocrine disruption for endocrinologists (and others). Endocrinology, 147, S1-S3.

Greenberg, T. C., \& Robert, E. (1982). Epidemiologic evidence for adverse effects of DES exposure during pregnancy. American Statistician, 36, 268-272.

Group, E. F., Jr. (1986). Environmental fate and aquatic toxicology studies on phthalate esters. Environmental Health Perspectives, 65, 337-340.

Guangen, H., Gangqiang, D., Xiaoming, L., Xiaofeng, W., Jianlong, H., Haitao, S., ... Leyan, D. (2011). Correlations of PCBs, DIOXIN, and PBDE with TSH in children's blood in areas of computer E-waste recycling. Biomedical and Environmental Sciences, 24, 112-116.

Guntur, A., \& Rosen, C. (2012). Bone as an endocrine organ. Endocrine Practice, 18, 758-762.

Hagiwara, H., Sugizaki, T., Tsukamoto, Y., Senoh, E., Goto, T., \& Ishihara, Y. (2008). Effects of alkylphenols on bone metabolism in vivo and in vitro. Toxicology Letters, 181, 13-18.

Harino, H., Fukushima, M., \& Kawai, S. (2000). Accumulation of butyltin and phenyltin compounds in various fish species. Archives of Environmental Contamination and Toxicology, 39, 13-19.

Harris, C. A., Henttu, P., Parker, M. G., \& Sumpter, J. P. (1997). The estrogenic activity of phthalate esters. In Vitro Environmental Health Perspectives, 105, 802-811.

Heindel, J. J., Blumberg, B., Cave, M., Machtinger, R., Mantovani, A., Mendez, M. A., ... Vom Saal, F. (2017). Metabolism disrupting chemicals and metabolic disorders. Reproductive Toxicology, 68, 3-33.

Hernando, M. D., Mezcua, M., Gómez, M. J., Malato, O., Agáera, A., \& Fernãindez-Alba, A. R. (2004). Comparative study of analytical methods involving gas chromatography-mass spectrometry after derivatization and gas chromatography-tandem mass spectrometry for the determination of selected endocrine disrupting compounds in wastewaters. Journal of Chromatography A, 1047, 129-135.

Hodsman, A. B., Hanley, D. A., Ettinger, M. P., Bolognese, M. A., Fox, J., Metcalfe, A. J., \& Lindsay, R. (2003). Efficacy and safety of human parathyroid hormone-(1-84) in increasing bone mineral density in postmenopausal osteoporosis. Journal of Clinical Endocrinology and Metabolism, 88, 5212-5220.

Hormann, A. M., Vom Saal, F. S., Nagel, S. C., Stahlhut, R. W., Moyer, C. L., Ellersieck, M. R., ... Taylor, J. A. (2014). Holding thermal receipt paper and eating food after using hand sanitizer results in high serum bioactive and urine total levels of bisphenol A (BPA). PLoS One, 9, e110509.

Hsieh, C. Y., Miaw, C. L., Hsieh, C. C., Tseng, H. C., Yang, Y. H., \& Yen, C. H. (2009). Effects of chronic 4-n-nonylphenol treatment on aortic vasoconstriction and vasorelaxation in rats. Archives of Toxicology, 83, 941-946.

Hsu, E. L., Sonn, K., Kannan, A., Bellary, S., Yun, C., Hashmi, S., ... Hsu, W. K. (2015). Dioxin exposure impairs BMP-2-mediated spinal fusion in a rat arthrodesis model. The Journal of Bone and Joint Surgery. American Volume, 97, 1003-1010.
Hwang, J. K., Min, K. H., Choi, K. H., Hwang, Y. C., Jeong, I. K., Ahn, K. J., ... Chang, J. S. (2013). Bisphenol A reduces differentiation and stimulates apoptosis of osteoclasts and osteoblasts. Life Sciences, 93, 367-372.

IARC (2012). International Agency for Research on Cancer. Pharmaceuticals. Diethylstilbestrol. A review of human carcinogens. IARC Monographs on the Evaluation of Carcinogenic Risks to Humans, 100A, 175-218.

Ikezuki, Y., Tsutsumi, O., Takai, Y., Kamei, Y., \& Taketani, Y. (2002). Determination of bisphenol A concentrations in human biological fluids reveals significant early prenatal exposure. Human Reproduction, 17, 2839-2841.

Iwata, M., Eshima, Y., Kagechika, H., \& Miyaura, H. (2004). The endocrine disruptors nonylphenol and octylphenol exert direct effects on T cells to suppress Th1 development and enhance Th2 development. Immunology Letters, 94, 135-139.

Jacobs, M. N., Marczylo, E. L., Guerrero-Bosagna, C., \& Rüegg, J. (2017). Marked for life: Epigenetic effects of endocrine disrupting chemicals. Annu Rev Environ Resour, 42, 105-160.

Jamsa, T., Viluksela, M., Tuomisto, J. T., Tuomisto, J., \& Tuukkanen, J. (2001). Effects of 2,3,7,8-tetrachlorodibenzo-p-dioxin on bone in two rat strains with different aryl hydrocarbon receptor structures. Journal of Bone and Mineral Research, 16, 1812-1820.

Jobling, S., Reynolds, T., White, R., Parker, M. G., \& Sumpter, J. P. (1995). A variety of environmentally persistent chemicals, including some phthalate plasticizers, are weakly estrogenic. Environmental Health Perspectives, 103, 582-587.

Jorgensen, E. M., Alderman, M. H., 3rd, \& Taylor, H. S. (2016). Preferential epigenetic programming of estrogen response after in utero xenoestrogen (bisphenol-A) exposure. FASEB Journal, 30, 3194-3201.

Kaludjerovic, J., \& Ward, W. E. (2008). Diethylstilbesterol has genderspecific effects on weight gain and bone development in mice. Journal of Toxicology and Environmental Health. Part A, 71, 1032-1042.

Kamei, S., Miyawaki, J., Sakayama, K., Yamamoto, H., \& Masuno, H. (2008). Perinatal and postnatal exposure to 4-tert-octylphenol inhibits cortical bone growth in width at the diaphysis in female mice. Toxicology, 252, 99-104.

Kannan, K., Corsolini, S., Focardi, S., Tanabe, S., \& Tatsukawa, R. (1996). Accumulation pattern of butyltin compounds in dolphin, tuna, and shark collected from Italian coastal waters. Archives of Environmental Contamination and Toxicology, 31, 19-23.

Kannan, K., Takahashi, S., Fujiwara, N., Mizukawa, H., \& Tanabe, S. (2010). Organotin compounds, including butyltins and octyltins, in house dust from Albany, New York, USA. Archives of Environmental Contamination and Toxicology. 58, 901-907.

Kim, J. C., Shin, H. C., Cha, S. W., Koh, W. S., Chung, M. K., \& Han, S. S. (2001). Evaluation of developmental toxicity in rats exposed to the environmental estrogen bisphenol A during pregnancy. Life Sciences, 69, 2611-2625.

Kirchner, S., Kieu, T., Chow, C., Casey, S., \& Blumberg, B. (2010). Prenatal exposure to the environmental obesogen tributyltin predisposes multipotent stem cells to become adipocytes. Molecular Endocrinology, 24, 526-539.

Kitraki, E., Nalvarte, I., Alavian-Ghavanini, A., \& Rüegg, J. (2015). Developmental exposure to bisphenol A alters expression and DNA methylation of Fkbp5, an important regulator of the stress response. Molecular and Cellular Endocrinology, 417, 191-199.

Korach, K. S., Metzler, M., \& McLachlan, J. A. (1978). Estrogenic activity in vivo and in vitro of some diethylstilbestrol metabolites and analogs. Proceedings of the National Academy of Sciences of the United States of America, 75, 468-471.

Korkalainen, M., Kallio, E., Olkku, A., Nelo, K., Ilvesaro, J., Tuukkanen, J., ... Viluksela, M. (2009). Dioxins interfere with differentiation of osteoblasts and osteoclasts. Bone, 44, 1134-1142. 
Koskela, A., Finnilä, M. A., Korkalainen, M., Spulber, S., Koponen, J., Håkansson, H., ... Viluksela, M. (2016). Effects of developmental exposure to perfluorooctanoic acid (PFOA) on long bone morphology and bone cell differentiation. Toxicology and Applied Pharmacology, 15, 14-21. 301

Kouzmenko, A., Ohtake, F., Fujiki, R., \& Kato, S. (2010). Hormonal gene regulation through DNA methylation and demethylation. Epigenomics, 2, 765-774.

Kumar, V., Green, S., Stack, G., Berry, M., Jin, J. R., \& Chambon, P. (1987). Functional domains of the human estrogen receptor. Cell, 51, 941-951.

Kung, M. H., Yukata, K., O'Keefe, R. J., \& Zuscik, M. J. (2012). Aryl hydrocarbon receptor-mediated impairment of chondrogenesis and fracture healing by cigarette smoke and benzo(a)pyrene. Journal of Cellular Physiology, 227, 1062-1070.

Kvalem, H. E., Brantsæter, A. L., Meltzer, H. M., Stigum, H., Thomsen, C., Haugen, M., ... Knutsen, H. K. (2012). Development and validation of prediction models for blood concentrations of dioxins and PCBs using dietary intakes. Environment International, 50, 15-21.

Lee, D. H., Lee, I. K., Steffes, M., \& Jacobs, D. R., Jr. (2007). Extended analyses of the association between serum concentrations of persistent organic pollutants and diabetes. Diabetes Care, 30, 1596-1598.

Lejonklou, M. H., Christiansen, S., Örberg, J., Shen, L., Larsson, S., Boberg, J., ... Lind, P. M. (2016). Low-dose developmental exposure to bisphenol A alters the femoral bone geometry in wistar rats. Chemosphere, 164, 339-346.

Leung, A. O. W., Zheng, J., Yu, C. K., Liu, W. K., Wong, C. K. C., Cai, Z., \& Wong, M. H. (2011). Polybrominated diphenyl ethers and polychlorinated dibenzo-p-dioxins and dibenzofurans in surface dust at an Ewaste processing site in Southeast China. Environmental Science \& Technology, 45, 5775-5782.

Lewis, R., Johns, L., \& Meeker, J. (2015). Serum biomarkers of exposure to perfluoroalkyl substances in relation to serum testosterone and measures of thyroid function among adults and adolescents from NHANES 2011-2012. International Journal of Environmental Research and Public Health, 12, 6098-6114.

Lin, L. Y., Wen, L. L., Su, T. C., Chen, P. C., \& Lin, C. Y. (2014). Negative association between serum perfluorooctane sulfate concentration and bone mineral density in US premenopausal women: NHANES, 20052008. Journal of Clinical Endocrinology and Metabolism, 99, 2173-2180.

Lin, S. E., Huang, J. P., Wu, L. Z., Wu, T., \& Cui, L. (2013). Prevention of osteopenia and dyslipidemia in rats after ovariectomy with combined aspirin and low-dose diethylstilbestrol. Biomedical and Environmental Sciences, 26, 249-257.

Lind, T., Lejonklou, M. H., Dunder, L., Rasmusson, A., Larsson, S., Melhus, H., \& Lind, P. M. (2017). Low-dose developmental exposure to bisphenol $A$ induces sex-specific effects in bone of Fischer 344 rat offspring. Environmental Research, 159, 61-68.

Lindsey, S., \& Papoutsakis, E. T. (2012). The evolving role of the aryl hydrocarbon receptor (AHR) in the normophysiology of hematopoiesis. Stem Cell Rev and Rep, 8, 1223-1235.

Luc, S., Buza-Vidas, N., \& Jacobsen, S. E. W. (2008). Delineating the cellular pathways of hematopoietic lineage commitment. Seminars in Immunology, 20, 213-220.

Mangelsdorf, D. J., Thummel, C., Beato, M., Herrlich, P., Schütz, G., Umesono, K., ... Evans, R. M. (1995). The nuclear receptor superfamily: The second decade. Cell, 83, 835-839.

Martens, J. H. A., Rao, N. A. S., \& Stunnenberg, H. G. (2011). Genome-wide interplay of nuclear receptors with the epigenome. Biochimica et Biophysica Acta/General Subjects, 1812, 818-823.

Masuyama, H., \& Hiramatsu, Y. (2004). Involvement of suppressor for Gal 1 in the ubiquitin/proteasome-mediated degradation of estrogen receptors. Journal of Biological Chemistry, 279, 12020-12026.
Masuyama, H., Inoshita, H., Hiramatsu, Y., \& Kudo, T. (2002). Ligands have various potential effects on the degradation of pregnane $X$ receptor by proteasome. Endocrinology, 143, 55-61.

Matthews, J., Celius, T., Halgren, R., \& Zacharewski, T. (2000). Differential estrogen receptor binding of estrogenic substances: A species comparison. Journal of Steroid Biochemistry and Molecular Biology, 74, 223-234.

Mayer, F. L., Stalling, D. L., \& Johnson, J. L. (1972). Phthalate esters as environmental contaminants. Nature, 238, 411-413.

McAnulty, P. A., \& Skydsgaard, M. (2005). Diethylstilbestrol (DES): Carcinogenic potential in Xpa-/-, Xpa-/-, p53+/-, and wild-type mice during 9 months' dietary exposure. Toxicologic Pathology, 33, 609-620.

McKee, R. H., Pavkov, K. L., Trimmer, G. W., Keller, L. H., \& Stump, D. G. (2006). An assessment of the potential developmental and reproductive toxicity of di-isoheptyl phthalate in rodents. Reproductive Toxicology, 21, 241-252.

Miettinen, H. M., Pulkkinen, P., Jämsä, T., Koistinen, J., Simanainen, U., Tuomisto, J., ... Viluksela, M. (2005). Effects of in utero and lactational TCDD exposure on bone development in differentially sensitive rat lines. Toxicological Sciences 85, 1003-1012.

Migliaccio, S., Newbold, R. R., Teti, A., Jefferson, W. J., Toverud, S. U., Taranta, A., ... Korach, K. S. (2000). Transient estrogen exposure of female mice during early development permanently affects osteoclastogenesis in adulthood. Bone, 27, 47-52.

Min, K., \& Min, J. (2014). Urinary phthalate metabolites and the risk of low bone mineral density and osteoporosis in older women. Journal of Clinical Endocrinology and Metabolism, 99, E1997-E2003.

Miyawaki, J., Kamei, S., Sakayama, K., Yamamoto, H., \& Masuno, H. (2008). 4-tert-octylphenol regulates the differentiation of C3H10T1/2 cells into osteoblast and adipocyte lineages. Toxicological Sciences, 102, 82-88.

Moors, S., Diel, P., \& Degen, G. H. (2006). Toxicokinetics of bisphenol A in pregnant DA/Han rats after single i.v. application. Archives of Toxicology, 80, 647-655.

Mustafa, A., Holladay, S. D., Goff, M., Witonsky, S. G., Kerr, R., Reilly, C. M., ... Gogal, R. M. (2008). An enhanced postnatal autoimmune profile in 24 week-old C57BL/6 mice developmentally exposed to TCDD. Toxicology and Applied Pharmacology, 232, 51-59.

Mårtensson, U. E. A., Salehi, S. A., Windahl, S., Gomez, M. F., Swärd, K., Daszkiewicz-Nilsson, J., ... Leeb-Lundberg, L. M. F. (2009). Deletion of the $\mathrm{G}$ protein-coupled receptor 30 impairs glucose tolerance, reduces bone growth, increases blood pressure, and eliminates estradiolstimulated insulin release in female mice. Endocrinology, 150, 687-698.

Naganawa, T., Xiao, L., Abogunde, E., Sobue, T., Kalajzic, I., Sabbieti, M., ... Hurley, M. M. (2006). In vivo and in vitro comparison of the effects of FGF-2 null and haplo-insufficiency on bone formation in mice. Biochemical and Biophysical Research Communications, 339, 490-498.

Naganawa, T., Xiao, L., Coffin, J. D., Doetschman, T., Sabbieti, M. G., Agas, D., \& Hurley, M. M. (2008). Reduced expression and function of bone morphogenetic protein-2 in bones of Fgf2 null mice. Journal of Cellular Biochemistry, 103, 1975-1988.

Naruse, M., Ishihara, Y., Miyagawa-Tomita, S., Koyama, A., \& Hagiwara, H. (2002). 3-Methylcholanthrene, which binds to the arylhydrocarbon receptor, inhibits proliferation and differentiation of osteoblasts in vitro and ossification in vivo. Endocrinology, 143, 3575-3581.

Naruse, M., Otsuka, E., Naruse, M., Ishihara, Y., Miyagawa-Tomita, S., \& Hagiwara, H. (2004). Inhibition of osteoclast formation by 3-methylcholanthrene, a ligand for arylhydrocarbon receptor: Suppression of osteoclast differentiation factor in osteogenic cells. Biochemical Pharmacology, 67, 119-127.

Nimrod, A. C., \& Benson, W. H. (1996). Environmental estrogenic effects of alkylphenol ethoxylates. Critical Reviews in Toxicology, 69, 335-364. 
Ohtake, F., Takeyama, K., Matsumoto, T., Kitagawa, H., Yamamoto, Y., Nohara, K., ... Kato, S. (2003). Modulation of oestrogen receptor signalling by association with the activated dioxin receptor. Nature, 423, 545-550.

Okey, A. B. (2007). An aryl hydrocarbon receptor odyssey to the shores of toxicology: The Deichmann Lecture, International Congress of Toxicology-XI. Toxicological Sciences, 98, 5-38.

Papoutsis, A. J., Selmin, O. I., Borg, J. L., \& Romagnolo, D. F. (2015). Gestational exposure to the AhR agonist 2,3,7,8-tetrachlorodibenzop-dioxin induces BRCA-1 promoter hypermethylation and reduces BRCA-1 expression in mammary tissue of rat offspring: Preventive effects of resveratrol. Molecular Carcinogenesis, 54, 261-269.

Pelch, K. E., Carleton, S. M., Phillips, C. L., \& Nagel, S. C. (2012). Developmental exposure to xenoestrogens at low doses alters femur length and tensile strength in adult mice. Biology of Reproduction, $86,69$.

Piekarz, A. V., \& Ward, W. E. (2007). Effect of neonatal exposure to genistein on bone metabolism in mice at adulthood. Pediatric Research, 61, 48-53.

Pohjanvirta, R., \& Tuomisto, J. (1994). Short-term toxicity of 2,3,7, 8-tetrachlorodibenzo-p-dioxin in laboratory animals: Effects, mechanisms and animal models. Pharmacological Reviews, 46, 483-549.

Post, G. B., Cohn, P. D., \& Cooper, K. R. (2012). Perfluorooctanoic acid (PFOA), an emerging drink- ing water contaminant: A critical review of recent literature. Environmental Research, 116, 93-117.

Rochester, J. R. (2013). Bisphenol A and human health: A review of the literature. Reproductive Toxicology, 42, 132-155.

Rosen, V., \& Wozney, J. M. (2002). Bone morphogenetic proteins. In Belizikian, J., Raisz, L. G., \& Rodan, G. (Eds.), Principles of bone biology (pp. 919-928). San Diego: Academic Press. 2nd edition.

Rowas, S. A., Haddad, R., Gawri, R., Al Ma'awi, A. A., Chalifour, L. E., Antoniou, J., \& Mwale, F. (2012). Effect of in utero exposure to diethylstilbestrol on lumbar and femoral bone, articular cartilage, and the intervertebral disc in male and female adult mice progeny with and without swimming exercise. Arthritis Research \& Therapy, 14, R17.

Ryan, E. P., Holz, J. D., Mulcahey, M., Sheu, T., Gasiewicz, T. A., \& Puzas, J. E. (2007). Environmental toxicants may modulate osteoblast differentiation by a mechanism involving the aryl hydrocarbon receptor. Journal of Bone and Mineral Research, 22, 1571-1580.

Sabbieti, M. G., Agas, D., Marchetti, L., Coffin, J. D., Xiao, L., \& Hurley, M. M. (2013). BMP-2 differentially modulates FGF-2 isoform effects in osteoblasts from newborn transgenic mice. Endocrinology, 154, 2723-2733.

Sabbieti, M. G., Agas, D., Marchetti, L., Santoni, G., Amantini, C., Xiao, L., ... Hurley, M. M. (2010). Signaling pathways implicated in PGF2alpha effects on Fgf2+/+ and Fgf2-/- osteoblasts. Journal of Cellular Physiology, 224, 465-474.

Sabbieti, M. G., Agas, D., Materazzi, S., Capacchietti, M., Materazzi, G., Hurley, M. M., ... Marchetti, L. (2008). Prostaglandin F2alpha involves heparan sulphate sugar chains and FGFRs to modulate osteoblast growth and differentiation. Journal of Cellular Physiology, 217, 48-59.

Sabbieti, M. G., Agas, D., Palermo, F., Mosconi, G., Santoni, G., Amantini, C., ... Marchetti, L. (2011). 4-Nonylphenol triggers apoptosis and affects $17-\beta$ estradiol receptors in calvarial osteoblasts. Toxicology, 290, 334-341.

Sabbieti, M. G., Agas, D., Santoni, G., Materazzi, S., Menghi, G., \& Marchetti, L. (2009). Involvement of p53 in phthalate effects on mouse and rat osteoblasts. Journal of Cellular Biochemistry, 107, 316-327.

Sabbieti, M. G., Agas, D., Xiao, L., Marchetti, L., Coffin, J. D., Doetschman, T., \& Hurley, M. M. (2009). Endogenous FGF-2 is critically important in PTH anabolic effects on bone. Journal of Cellular Physiology, 219, 143-151.

Sabbieti, M. G., Marchetti, L., Censi, R., Lacava, G., \& Agas, D. (2017). Role of PTH in bone marrow niche and HSC regulation . Current Stem Cell Reports, 3, 210. https://doi.org/10.1007/s40778-017-0091-7.
Saillenfait, A. M., Gallissot, F., \& Sabaté, J. P. (2009). Differential developmental toxicities of di-n-hexyl phthalate and dicyclohexyl phthalate administered orally to rats. Journal of Applied Toxicology, 29, 510-521.

Saillenfait, A. M., Roudot, A. C., Gallissot, F., \& Sabaté, J. P. (2011). Prenatal developmental toxicity studies on di-n-heptyl and di-n-octyl phthalates in Sprague-Dawley rats. Reproductive Toxicology, 32, 268-276.

Sato, S., Shirakawa, H., Tomita, S., Ohsaki, Y., Haketa, K., Tooi, O., ... Komai, M. (2008). Low-dose dioxins alter gene expression related to cholesterol biosynthesis, lipogenesis, and glucose metabolism through the aryl hydrocarbon receptor-mediated pathway in mouse liver. Toxicology and Applied Pharmacology, 229, 10-19.

Schantz, S. L., \& Widholm, J. J. (2001). Cognitive effects of endocrinedisrupting chemicals in animals. Environmental Health Perspectives, 109, 1197-1206.

Schlezinger, J. J., Howard, G. J., Hurst, C. H., Emberley, J. K., Waxman, D. J., Webster, T., \& Sherr, D. H. (2004). Environmental and endogenous peroxisome proliferator-activated receptor gamma agonists induce bone marrow B cell growth arrest and apoptosis: Interactions between mono(2-ethylhexyl) phthalate, 9-cis-retinoic acid, and 15deoxy-Delta12,14-prostaglandin J2. Journal of Immunology, 173, 3165-3177.

Shen, H., Ding, G., Han, G., Wang, X., Xu, X., Han, J., ... Lu, W. (2010). Distribution of PCDD/Fs, PCBs, PBDEs and organochlorine residues in children's blood from Zhejiang, China. Chemosphere, 80, 170-175.

Sholts, S. B., Korkalainen, M., Simanainen, U., Miettinen, H. M., Håkansson, H., \& Viluksela, M. (2015). In utero/lactational and adult exposures to 2,3,7,8-tetrachlorodibenzo-p-dioxin (TCDD) show differential effects on craniofacial development and growth in rats. Toxicology, 337, 30-38.

Shoucri, B. M., Martinez, E. S., Abreo, T. J., Hung, V. T., Moosova, Z., Shioda, T., \& Blumberg, B. (2017). Retinoid $X$ receptor activation alters the chromatin landscape to commit mesenchymal stem cells to the adipose lineage. Endocrinology, 158, 3109-3125.

Singh, S. U. N., Casper, R. F., Fritz, P. C., Sukhu, B., Ganss, B., Girard, B., ... Tenenbaum, H. C. (2000). Inhibition of dioxin effects on bone formation in vitro by a newly described aryl hydrocarbon receptor antagonist, resveratrol. Journal of Endocrinology, 167, 183-195.

Smith, B. W., Rozelle, S. S., Leung, A., Ubellacker, J., Parks, A., Nah, S. K., ... Murphy, G. J. (2013). The aryl hydrocarbon receptor directs hematopoietic progenitor cell expansion and differentiation. Blood, 122, 376-385.

Smith, E. P., Boyd, J., Frank, G. R., Takahashi, H., Cohen, R. M., Specker, B., ... Korach, K. S. (1994). Estrogen resistance caused by a mutation in the estrogen-receptor gene in a man. New England Journal of Medicine, 331, 1056-1061.

Smith, J. T., Schneider, A. D., Katchko, K. M., Yun, C., \& Hsu, E. L. (2017). Environmental factors impacting bone-relevant chemokines. Frontiers in Endocrinology, 8, 22.

Spelsberg, T. C., Subramaniam, M., Riggs, B. L., \& Khosla, S. (1999). The actions and interactions of sex steroids and growth factors/cytokines on the skeleton. Molecular Endocrinology, 13, 819-828.

Staples, C. A., Dome, P. B., Klecka, G. M., O’Block, S. T., \& Harris, L. R. (1998). A review of the environmental fate, effects, and exposures of bisphenol A. Chemosphere, 36, 2149-2173.

Stein, S. J., \& Baldwin, A. S. (2013). Deletion of the NF-kB subunit p65/ RelA in the hematopoietic compartment leads to defects in hematopoietic stem cell function. Blood, 121, 5015-5024.

Strong, A. L., Miller, D. F. B., Buechlein, A. M., Fang, F., Glowacki, J., McLachlan, J. A., ... Bunnell, B. A. (2016). Bisphenol A alters the self-renewal and differentiation capacity of human bone-marrowderived mesenchymal stem cells. Endocrine Disruptors, 4, e1200344.

Supornsilchai, V., Jantarat, C., Nosoognoen, W., Pornkunwilai, S., Wacharasindhu, S., \& Soder, O. (2016). Increased levels of bisphenol 
A (BPA) in Thai girls with precocious puberty. Journal of Pediatric Endocrinology and Metabolism, 29, 1233-1239.

Swedenborg, E., Ruegg, J., Makela, S., \& Pongratz, I. (2009). Endocrine disruptive chemicals: Mechanisms of action and involvement in metabolic disorders. Journal of Molecular Endocrinology, 43, 1-10.

Tabb, M. M., \& Blumberg, B. (2006). New modes of action for endocrinedisrupting chemicals. Molecular Endocrinology, 20, 475-482.

Titus-Ernstoff, L., Troisi, R., Hatch, E. E., Palmer, J. R., Hyer, M., Kaufman, R., ... Hoover, R. N. (2010). Birth defects in the sons and daughters of women who were exposed in utero to diethylstilbestrol (DES). International Journal of Andrology, 2, 377-384.

Tiwari, D., Kamble, J., Chilgunde, S., Patil, P., Maru, G., Kawle, D., ... Vanage, G. (2012). Clastogenic and mutagenic effects of bisphenol A: An endocrine disruptor. Mutation Research/DNA Repair, 743, 83-90.

Toda, K., Miyaura, C., Okada, T., \& Shizuta, Y. (2002). Dietary bisphenol A prevents ovarian degeneration and bone loss in female mice lacking the aromatase gene (Сур19). European Journal of Biochemistry, 269, 2214-2222.

Treffers, P. E., Hanselaar, A. G., Helmerhorst, T. J., Koster, M. E., \& van Leeuwen, F. E. (2001). Consequences of diethylstilbestrol during pregnancy; 50 years later still a significant problem. Nederlands Tijdscrift Voor Geneeskunde, 145, 675-680.

Tsai, K. S., Yang, R. S., \& Liu, S. H. (2004). Benzo[a]pyrene regulates osteoblast proliferation through an estrogen receptor-related cyclooxygenase-2 pathway. Chemical Research in Toxicology, 17, 679-684.

Tsuchiya, Y., Nakajima, M., \& Yokoi, T. (2005). Cytochrome P450mediated metabolism of estrogens and its regulation in human. Cancer Letters, 227, 115-124.

Tsukamoto, Y., Ishihara, Y., Miyagawa-Tomita, S., \& Hagiwara, H. (2004). Inhibition of ossification in vivo and differentiation of osteoblasts in vitro by tributyltin. Biochemical Pharmacology, 68, 739-746.

Tuomisto, J. (2001). Are dioxins a health problem in Finland?. Duodecim, 117, 245-246.

Voronov, I., Li, K., Tenenbaum, H. C., \& Manolson, M. F. (2008). Benzo[a] pyrene inhibits osteoclastogenesis by affecting RANKL-induced activation of NF-kappaB. Biochemical Pharmacology, 75, 2034-2044.

Wang, J. L., Li, C. S., Lin, K. L., Chou, C. T., Hsieh, C. H., Chang, C. H., ... Jan, C. R. (2005). Nonylphenol-induced $\mathrm{Ca} 2+$ elevation and $\mathrm{Ca} 2+-$ independent cell death in human osteosarcoma cells. Toxicology Letters, 160, 76-83.

Watson, C. S., Jeng, Y. J., \& Kochukov, M. Y. (2010). Nongenomic signaling pathways of estrogen toxicity. Toxicological Sciences, 115, 1-11.
Watt, J., \& Schlezinger, J. J. (2015). Structurally-diverse, PPAR $\gamma$ activating environmental toxicants induce adipogenesis and suppress osteogenesis in bone marrow mesenchymal stromal cells. Toxicology, 331, 66-77.

Welshons, W. V., Nagel, S. C., \& vom Saal, F. S. (2006). Large effects from small exposures. III: Endocrine mechanisms mediating effects of bisphenol A at levels of human exposure. Endocrinology, 147, S56-S69.

Wetherill, Y. B., Akingbemi, B. T., Kanno, J., McLachlan, J. A., Nadal, A., Sonnenschein, C., ... Belcher, S. M. (2007). In vitro molecular mechanisms of bisphenol A action. Reproductive Toxicology, 24, 178-198.

Windahl, S. H., Andersson, G., \& Gustafsson, J. Å. (2002). Elucidation of estrogen receptor function in bone with the use of mouse models. Trends in Endocrinology and Metabolism, 13, 195-200.

World Health Organization (1996). Levels of PCBs, PCDDs and PCDFs in human milk. Second round of WHOcoordinated exposure study, Copenhagen, Denmark: WHO European Center for Environment and Health. Environmental Health in Europe No. 3

Xu, Z. X., Liu, J., Gu, L. P., Huang, B., \& Pan, X. J. (2017). Biological effects of xenoestrogens and the functional mechanisms via genomic and nongenomic pathways. Environmental Reviews, 25, 306-322.

Ye, R., Holland, W. L., Gordillo, R., Wang, M., Wang, Q. A., Shao, M., ... Scherer, P. E. (2014). Adiponectin is essential for lipid homeostasis and survival under insulin deficiency and promotes beta-cell regeneration. Elife3, 3. https://doi.org/10.7554/eLife.03851.

Yu, W. G., Liu, W., Jin, Y. H., Liu, X. H., Wang, F. Q., Liu, L., \& Nakayama, S. F. (2009). Prenatal and postnatal impact of perfluorooctane sulfonate (PFOS) on rat development: A cross-foster study on chemical burden and thyroid hormone system. Environmental Science and Technology, 43, 8416-8422.

Zhou, R., Chen, F., Chang, F., Bai, Y., \& Chen, L. (2013). Persistent overexpression of DNA methyltransferase 1 attenuating GABAergic inhibition in basolateral amygdala accounts for anxiety in rat offspring exposed perinatally to low-dose bisphenol A. Journal of Psychiatric Research, 47, 1535-1544.

How to cite this article: Agas D, Lacava G, Sabbieti MG. Bone and bone marrow disruption by endocrine-active substances.

J Cell Physiol. 2019;234:192-213.

https://doi.org/10.1002/jcp.26837 